\title{
Stock Market Uncertainty and the Stock-Bond Return Relation ${ }^{1}$
}

\author{
Robert Connolly ${ }^{a}$, Chris Stivers $^{b}$, and Licheng Sun ${ }^{c}$ \\ ${ }^{a}$ Kenan-Flagler Business School \\ University of North Carolina at Chapel Hill \\ Chapel Hill, NC \\ $b$ Terry College of Business \\ University of Georgia \\ Athens, GA \\ ${ }^{c}$ School of Business \\ Penn State Erie \\ Erie, $\mathrm{PN}$
}

June 20, 2003

\footnotetext{
${ }^{1}$ Connolly, connollr@bschool.unc.edu; Stivers, cstivers@terry.uga.edu; Sun, lsun@arches.uga.edu. We thank Stephen Brown (the editor), Jennifer Conrad, Jerry Dwyer, Mark Fisher, Paskalis Glabadanidis, Mark Kamstra, Bill Lastrapes, Marc Lipson, Alex Philipov, Joe Sinkey, Paula Tkac, an anonymous JFQA referee, and participants from seminars at the 2002 Western Finance Association meetings, the 2002 Financial Management Association meetings, the 2001 Atlanta Federal Reserve Bank's All Georgia Conference, and the University of Georgia for comments and helpful discussions. We also thank the Financial Management Association for selecting an earlier version of this paper as the winner of the 2002 Best Paper Award in Investments at the October 2002 FMA meeting. Stivers is also a Visiting Scholar at the Federal Reserve Bank of Atlanta. The views expressed in this article are those of the authors and do not necessarily reflect the position of the Federal Reserve Bank of Atlanta or the Federal Reserve System.
} 


\title{
Stock Market Uncertainty and the Stock-Bond Return Relation
}

\begin{abstract}
We examine whether time-variation in the co-movements of daily stock and Treasury bond returns can be linked to non-return-based measures of stock market uncertainty, specifically the implied volatility from equity index options and detrended stock turnover. From a forward-looking perspective, we find a negative relation between the uncertainty measures and the future correlation of stock and bond returns. From a contemporaneous perspective, we find that bond returns tend to be high (low), relative to stock returns, during days when implied volatility increases (decreases) substantially and during days when stock turnover is unexpectedly high (low). Our findings suggest that stock market uncertainty has important cross-market pricing influences and that stock-bond diversification benefits increase with stock market uncertainty.
\end{abstract}




\section{Introduction}

It is well known that stock and bond returns exhibit a modest positive correlation over the long term. However, there is substantial time-variation in the relation between stock and bond returns over the short term, including sustained periods of negative correlation (Fleming, Kirby, and Ostdiek (2003), Gulko (2002), Li (2002), and Hartmann, Straetmans, and Devries (2001)). Characterizing this time-variation has important implications for understanding the economics of joint stock-bond price formation and may have practical applications in asset allocation and risk management.

In this paper, we study time-variation in the relation between daily stock and Treasury bond returns over 1986 to 2000 with a special interest in periods with a negative stock-bond return correlation. We extend prior work by examining whether non-return-based measures of stock market uncertainty can be linked to variation in the stock-bond return relation. Our motivation follows from recent literature on dynamic cross-market hedging (see, e.g., Fleming, Kirby, and Ostdiek (1998), Kodres and Pritsker (2002), and Chordia, Sarkar, and Subrahmanyam (2001)) and stock market uncertainty (see, e.g., Veronesi (1999) and (2001), and David and Veronesi (2001) and (2002)).

Most prior literature on joint stock-bond pricing has taken a traditional, fundamental approach and examined monthly or annual return data. This approach is well represented by Campbell and Ammer (CA) (1993). ${ }^{1}$ CA discuss several offsetting effects behind the correlation between stock and bond returns. First, variation in real interest rates may induce a positive correlation since the prices of both assets are negatively related to the discount rate. Second, variation in expected inflation may induce a negative correlation since increases in inflation are bad news for bonds and ambiguous news for stocks. Third, common movements in future expected returns may induce a positive correlation. The net effect in their monthly return sample over 1952 to 1987 is a small positive correlation between stock and bond returns $(\rho=0.20)$.

Thus, in the fundamental approach of CA, the only factor that may induce a negative correlation between stock and bond returns is a differential response to inflation expectations. Yet, the 1986 to 2000 period experienced both relatively low, stable inflation and sizable time-variation in the stock-

\footnotetext{
${ }^{1}$ Related earlier work includes Shiller and Beltratti (1992), Fama and French (1989), Barsky (1989), and Keim and Stambaugh (1986). More recent work include Bekaert and Grenadier (2001), Scruggs and Glabadanidis (2001), and Mamaysky (2002), see Section II for additional discussion.
} 
bond return relation, including sustained periods of negative correlation. While heteroskedasticity can induce time-variation in observed correlations (Forbes and Rigobon (2002)), heteroskedasticity alone cannot explain why two series that normally have a positive correlation occasionally have periods of negative correlation. This suggests other pricing influences may be important, such as cross-market hedging where shocks in one asset market may generate pricing influences in other nonshocked asset markets. The notion of cross-market hedging and flight-to-quality (and from quality) is also frequently mentioned in the popular press. For example, a Wall Street Journal article from November 4, 1997 (during the Asian financial crisis) speculated that the observed decoupling between the stock and bond markets was related to the high stock volatility and uncertain economic times.

In our empirical study, we examine daily stock and U.S. Treasury bond returns over 1986 to 2000. As indicated in Figure 1, Panel A, the stock-bond return correlation in this period is typically positive, but there are times of sustained negative correlation. Our empirical work examines whether the stock-bond return relation varies with two measures of stock market uncertainty suggested by the literature. First, we use the implied volatility from equity index options, specifically the Chicago Board Option Exchange's Volatility Index (VIX). ${ }^{2}$ Existing literature suggests that the implied volatility may reflect both the level and the uncertainty of the expected future stock volatility. Second, we use abnormal stock turnover. Prior work has argued that turnover may reflect dispersion-in-beliefs across investors or may be associated with changes in the investment opportunity set, both possibilities suggest a link between abnormal turnover and stock market uncertainty. Thus, we consider a broad notion of stock market uncertainty that includes the following (at least in principle): (1) the expected level of future stock volatility, (2) the uncertainty about future stochastic stock volatility, (3) economic-state uncertainty in the sense of Veronesi (1999) and David and Veronesi (2002), and (4) financial market uncertainty associated with financial crises (such as the 1997 Asian crisis and the 1998 Russian crisis). In Sections II and III, we further discuss the ideas behind our empirical questions and our proposed measures of stock market uncertainty.

We focus on two distinct, but related, empirical questions. The first question has a forwardlooking focus and asks whether variation in the relative level of stock market uncertainty is informative about the future stock-bond return relation. If periods with high stock uncertainty tend to

\footnotetext{
${ }^{2}$ The CBOE's Volatility Index is also commonly referred to as a market "Fear Index".
} 
have more frequent revisions in investors' estimates of stock risk and the relative attractiveness of stocks versus bonds, then higher stock market uncertainty suggests a higher probability of observing a negative stock-bond return correlation in the near future. Our second empirical question has a contemporaneous focus and asks whether a day's change in stock market uncertainty is associated with differences in the stock-bond return relation. This question further evaluates the empirical relevance of cross-market hedging and addresses the notion of flight-to(from)-quality with increased (decreased) stock uncertainty.

Our empirical investigation uncovers several striking results. First, we find a negative relation between our uncertainty measures and the future correlation between stock and bond returns. For example, when VIX $_{t-1}$ is greater than $25 \%$ (about $19 \%$ of the days) then there is a $36.5 \%$ chance of observing a subsequent negative correlation between stock and bond returns over the next month (days $t$ to $t+21$ ). ${ }^{3}$ However, when $\operatorname{VIX}_{t-1}$ is less than $20 \%$ (about $54 \%$ of the days) then there is only a $6.1 \%$ chance of observing a subsequent negative correlation between stock and bond returns over the next month. We find qualitatively similar results with our detrended stock turnover measure (DTVR), across subperiods, and in alternate empirical frameworks.

Second, we find that bond returns tend to be high (low), relative to stocks, during periods when VIX increases (decreases) and during periods when unexpected stock turnover is high (low). For example, for the days when the unexpected stock turnover exceeds its $95^{\text {th }}$ percentile, the average daily bond return is over four times its unconditional mean.

Finally, we also explore a two-state regime-shifting approach to modeling time-variation in the stock-bond return relation. Our regime-shifting results demonstrate that: (1) a simple regimeswitching model also picks up statistically reliable time-variation in the stock-bond return relation, (2) the probability of switching from one regime to another depends on the lagged VIX and our lagged DTVR in a manner consistent with our other findings, and (3) inflation behavior exhibits little variation across the regimes.

Overall, our findings suggest that stock market uncertainty has cross-market pricing influences that play an important role in joint stock-bond price formation. Our findings also suggest that

\footnotetext{
${ }^{3}$ All the representative results in our introduction use 10-year T-bond returns and subsequent 22-trading-day correlations (over days $t$ to $t+21$ ). We choose 22 trading days because this horizon corresponds to the option maturity for VIX and because much prior literature has formed monthly statistics from daily observations.
} 
implied volatility and stock turnover may prove useful for financial applications that need to understand and predict stock and bond return co-movements. Finally, our empirical results suggest that the benefits of stock-bond diversification increase during periods of high stock market uncertainty.

This study is organized as follow. Section II further discusses the related literature and Section III reviews our primary empirical questions and our measures of stock market uncertainty. Section IV presents the data. Next, sections V and VI examine stock-bond return dynamics jointly with VIX and stock turnover, respectively. Section VII examines a regime-shifting approach and Section VIII concludes.

\section{Additional Discussion of the Literature}

Here we briefly discuss related literature which provides important perspective and intuition for our empirical investigation. First, both Fleming, Kirby, and Ostdiek (1998) and Kodres and Pritsker (2002) consider pricing influences related to cross-market hedging. Fleming, Kirby, and Ostdiek estimate a model on daily returns that takes cross-market-hedging effects into account and find that information linkages in the stock and bond markets may be greater than previously thought. Kodres and Pritsker propose a rational expectations model of financial contagion. Their model is designed to describe price movements over modest periods of time during which macroeconomic conditions can be taken as given. With wealth effects and asset substitution effects, a shock in one asset market may generate cross-market asset rebalancing with pricing influences in the non-shocked asset markets.

Second, dynamic cross-market hedging seems likely to be related to time-varying stock market uncertainty in the sense of Veronesi (1999) and (2001) and David and Veronesi (2001) and (2002). These papers feature state-uncertainty in a two-state economy where dividend growth shifts between unobservable states. The economic-state uncertainty is important in understanding price formation and return dynamics. During times of higher state-uncertainty, Veronesi (1999) predicts that new information may receive relatively higher weighting, which may induce time-varying volatility and volatility clustering. Veronesi (2001) introduces the idea of "aversion to state-uncertainty". Regarding bonds and stock volatility, this paper states, "Intuitively, aversion to state-uncertainty generates a high equity premium and a high return volatility because it increases the sensitivity of 
the marginal utility of consumption to news. In addition, it also lowers the interest rate because it increases the demand for bonds from investors who are concerned about the long-run mean of their consumption." David and Veronesi (2001) test whether the volatility and covariance of stock and bond returns vary with uncertainty about future inflation and earnings. Their uncertainty measures are derived both from survey data (at the semi-annual and quarterly frequency) and from their model estimation (at the monthly horizon). They find that uncertainty appears more important than the volatility of fundamentals in explaining volatility and covariances. David and Veronesi (2002) argue that economic-uncertainty should be positively related to the implied volatility from options.

Third, Chordia, Sarkar, and Subrahmanyam (2001) provide evidence consistent with a linkage between dynamic cross-market hedging and uncertainty. They examine both trading volume and bid-ask spreads in the stock and bond market over the June 1991 to December 1998 period and find that the correlation between stock and bond spreads and volume-changes increases dramatically during crises (relative to normal times). During periods of crises, they also find that there is a decrease in mutual fund flows to equity funds and an increase in fund flows to government bond funds. Their results are consistent with increased investor uncertainty leading to frequent and correlated portfolio reallocations during financial crises.

Finally, see Bekaert and Grenadier (2001) and Mamaysky (2002) for examples of recent work that jointly model stock and bond prices in a formal structural economic model. Both papers jointly model stock and bond prices as an affine function of a set of underlying state variables. These papers are interested in the common movement of expected returns for both stocks and bonds and identifying common and asset specific risks. The nature of these studies leads the authors to examine longer horizon returns in the empirical part of their papers (monthly and annual returns). While their models do not seem well-suited for direct application in modeling time-variation in daily stock-bond return dynamics, the models do provide useful intuition that supports our asset pricing discussion in Section III.A. First, Mamaysky proposes an economy where there are certain risk factors that are common to both stock and bonds, and another set of risk factors that are unique to stocks. We adopt this setup in our subsequent discussion concerning common and stock-specific risk factors. Bekaert and Grenadier investigate stock and bond prices within the joint framework of an affine model of term structure, present-value pricing of equities, and consumption-based 
asset pricing. They study three different economies and find that the "Moody" investor economy provides the best fit of the actual unconditional correlation between stock and bond returns. In this economy, prices are determined by dividend growth, inflation, and stochastic risk aversion where risk aversion is likely to be negatively correlated with shocks to dividend growth. This suggests that shocks to dividend growth may be associated with changing risk-premia and, possibly, changes in cross-market hedging between stocks and bonds.

\section{Empirical Questions and Measuring Stock Market Uncertainty}

\section{A. Primary Empirical Questions}

To provide intuition for our empirical investigation, here we discuss financial asset returns from a simple fundamental perspective where stock and bond prices can be represented as the expectation of future cash flows discounted at risk-adjusted discount rates. For stocks, both the future cash flows and discount rates are stochastic and may change over time as economic conditions and risk changes; whereas, for default-free government bonds, only the discount rates are stochastic. The discount rates reflect both a risk-free discount rate and a risk-premium, where cross-sectional variation in the risk-premia may be due to both contemporaneous risk differentials (in the sense of the single-period Capital Asset Pricing Model of Sharpe and Lintner) and hedging influences (in the sense of intertemporal asset pricing from Merton (1973)).

As observed in U.S. return data over long sample periods, consider the case where the unconditional expected returns of stocks are greater than those of bonds (due to the higher risk of stocks) and where the unconditional correlation between stock and bond returns is modestly positive (due to common exposure to the risk-free discount rate and a common co-movement in expected monthly returns over long periods, as documented in Fama and French (1989)). Given these unconditional return distributions, we are interested in characterizing time-variation in the co-movements between daily stock and bond returns.

We are especially interested in periods of sustained negative correlation over samples when inflation was both modest and stable (such as our study's 1986 to 2000 period). Since the expected component of daily returns is tiny compared to the daily volatility, our study does not rely on a formal model that jointly specifies the expected returns of stocks and bonds. Rather, our study is 
about characterizing co-movements in the unexpected component of daily stock and bond returns, where co-movements in the underlying risk-premia and expected cash flows are what is important (rather than the level of the risk-premia).

For example, consider a joint stock-bond asset pricing model with two sources of risk, one joint between stocks and bonds and one unique to stocks. When the risk of the stock-specific factor increases, ceteris paribus, the stock's expected return should go up, which would generate a contemporaneous decline in stock prices and an observed negative stock return for the day. Further, with cross-market hedging, bonds may become more attractive because investors are looking to hedge this increase in the stock-specific risk. Thus, the risk-premia of the bonds could actually decline with increased risk in the stock-specific factor, which would generate a contemporaneous increase in bond prices and an observed positive bond return for the day. Further, in some economic states, shocks to expected future cash flows from stocks may be negatively correlated with stock risk-premia and positively correlated with bond risk-premia, which could also generate a decoupling in stock and bond price dynamics. Thus, as in Kodres and Pritsker (2002), shocks in one market may generate pricing influences in another market, even if the news in the shocked market appears to have no direct relevance in the non-shocked market.

Our empirical work is primarily motivated by the seven papers listed in paragraph two of our introduction. In our view, the intuition from these papers suggests a notion of stock market uncertainty where higher uncertainty is associated with more frequent revisions in investors' assessment of stock risk and the relative attractiveness of stocks versus bonds. If so, then during times of higher stock market uncertainty, it seems plausible that a temporary negative stock-bond return correlation is more likely to be observed. Even holding inflation constant, such a temporary negative correlation could be consistent with both the unconditional positive correlation and the common co-movement in the monthly expected returns of stocks and bonds over very long periods. This possibility provides one interpretation for our findings and serves as a motivating framework for our empirical investigation.

Our empirical work examines daily stock and bond returns. We make this choice for several reasons. First, this choice follows from our discussion above, where temporary negative correlations in high frequency returns may co-exist with a long-term unconditional positive correlation. Second, daily returns provide the many observations needed to measure return dynamics that may differ 
during financial crises with durations of weeks or months. Third, daily expected returns are essentially zero, so our results on short-term daily return correlations are not sensitive to the selection of any particular asset-pricing model for expected returns. Fourth, sizable changes in stock market uncertainty may occur over a trading day. For example, in our sample, VIX changes by $15 \%$ or more for 94 different days, by $10 \%$ or more for 303 different days, and by $5 \%$ or more for 1,113 days. ${ }^{4}$ Fifth, the model in Kodres and Pritsker (2002) is meant to apply to short horizons. Finally, the use of daily data follows from Fleming, Kirby, and Ostdiek (1998). We investigate the following two primary empirical questions.

\section{Empirical Question One (EQ1): Can the relative level of stock market uncertainty} provide forward-looking information about future stock-bond return co-movements?

We evaluate whether the co-movements between daily stock and bond returns are reliably related to our lagged measures of stock market uncertainty. Our above discussion suggests that higher stock market uncertainty may be associated with a higher probability of a subsequent negative correlation in the near future. The null hypothesis is that time-varying correlations may be observed in daily returns, but it is an ex post phenomenon and the correlations cannot be linked to lagged, nonreturn-based measures of stock market uncertainty.

We stress that EQ1 does not test a simple flight-to-quality (FTQ) hypothesis that assumes abrupt, cleanly defined shocks to the stock market with a quick and complete responses in portfolio rebalancing and cross-market hedging. Under a simple FTQ hypothesis, adjustments should be essentially contemporaneous and lagged measures of uncertainty seem unlikely to be informative about future stock-bond return dynamics. Thus, EQ1 considers a more complex world where timevarying uncertainty may have cross-market pricing influences with forward-looking implications.

Empirical Question Two (EQ2): Is the daily change in stock market uncertainty associated with variation in the co-movement between stock and bond returns?

In contrast to the forward-looking implications of EQ1, EQ2 has a contemporaneous focus. We evaluate whether the co-movement between stock and bond returns varies with the contemporaneous daily change in our measures of stock market uncertainty. Our above discussion suggests that increases in stock market uncertainty may be associated with higher bond returns, relative to stock

\footnotetext{
${ }^{4} \mathrm{By}$ a change here, we mean $\left(V I X_{t}-V I X_{t-1}\right) / V I X_{t-1}$, where $V I X_{t}$ is the implied volatility level at the end-ofthe-day.
} 
returns. Tests of this sort may provide further evidence about the empirical relevance of crossmarket hedging and also address the notion of flight-to(from)-quality with increased (decreased) stock uncertainty. Here, the null hypothesis is that changes in non-return-based measures of stock market uncertainty are not reliably related to the contemporaneous stock and bond returns.

\section{B. Stock Market Uncertainty and the Implied Volatility of Equity Index Options}

For our primary measure of perceived stock market risk or uncertainty, we use the implied volatility index (VIX) from the Chicago Board Option Exchange. It provides an objective, observable, and dynamic measure of stock market uncertainty. Recent studies find that the information in implied volatility provides the best volatility forecast and largely subsumes the volatility information from historical return shocks, including volatility measures from 5-minute intraday returns (Blair, Poon, and Taylor (2001), Christensen and Prabhala (1998), and Fleming (1998)).

Under the standard Black-Scholes assumptions, implied volatility should only reflect expected stock market volatility. However, the Black-Scholes implied volatility of equity index options has been shown to be biased high. Coval and Shumway (2001) and Bakshi and Kapadia (2003) present evidence that option prices may also contain a component that reflects the risk of stochastic volatility. If options are valuable as hedges against unanticipated increases in volatility, then option prices may be higher than expected under a Black-Scholes world of known volatility. If so, option prices would typically yield a Black-Scholes implied volatility that is higher than realized volatility, which could explain the well-known bias and suggests that the standard implied volatility may also comove with the uncertainty about future stochastic volatility.

David and Veronesi (2002) present an option-pricing model that incorporates economic-state uncertainty. Their model generates a positive association between investor's uncertainty about fundamentals and the implied volatility in traded options. Their arguments provide further motivation for our use of the implied volatility from equity index options.

\section{Stock Market Uncertainty and Stock Turnover}

We also evaluate stock turnover as a second measure of stock market uncertainty. Prior literature suggests several reasons for turnover. These include asymmetric information with disperse beliefs across investors, changes in investment opportunity sets outside the traded stock market, and 
changes in the investment opportunity set of traded stocks (or changing stock return distributions). For example, Wang (1994) presents a dynamic model of competitive trading volume where volume conveys important information about how assets are priced in the economy. One prediction from Wang is that "the greater the information asymmetry (and diversity in expectations), the larger the abnormal trading volume when public news arrives." In Chen, Hong, Stein (2001), periods with relatively heavy volume are likely to be periods with large differences of opinion across investors. Also, see Harris and Raviv (1993) and Shalen (1993) for further discussion that relates turnover to heterogeneous information and beliefs; Heaton and Lucas (1996) and Wang (1994) for discussion

that relates turnover to changes in investment opportunity sets; and Lo and Wang (2000) for additional motives for trading volume.

Thus, relatively high stock turnover may be associated with more diverse beliefs across investors or changes in the investment opportunity set. It seems plausible to describe such times as having greater stock market uncertainty. Thus, we examine the relative level of stock turnover (detrended turnover) as a second metric that may reflect variation in the relative level of stock market uncertainty.

\section{Data Description and Statistics}

\section{A. Returns and Implied Volatility}

We examine daily data over the 1986 to 2000 period in our analysis because the CBOE's VIX is first reported in 1986. This period is also attractive because inflation was modest over the entire sample. This suggests that changes in inflation expectations are unlikely to be the primary force behind the striking time-series variation that we document in the stock-bond return relation. In our subsequent empirical testing, we also evaluate the following subperiods: 1988 to 2000 (to avoid econometric concerns that our empirical results might be dominated by the October 1987 stock market crash), 1/86 to $6 / 93$ (the first-half subperiod), and 7/93 to 12/00 (the second-half subperiod).

The CBOE's VIX, described by Fleming, Ostdiek, and Whaley (1995), represents the implied volatility of an at-the-money option on the S\&P 100 index with 22 trading days to expiration. It is constructed by taking a weighted average of the implied volatilities of eight options, calls and puts at the two strike prices closest to the money and the nearest two expirations (excluding options 
within one week of expiration). Each of the eight component implied volatilities is calculated using a binomial tree that accounts for early exercise and dividends. For daily bond returns, we analyze both 10-year U.S. Treasury notes and 30-year U.S. Treasury bonds. We calculate implied returns from the constant maturity yield from the Federal Reserve. Hereafter, we do not distinguish between notes and bonds in our terminology and refer to both the 10-year note and the 30-year bond as "bonds". We choose longer-term securities over shorter-term securities because long-term bonds are closer maturity substitutes to stocks and because monetary policy operations are more likely to have a confounding influence on shorter-term securities. ${ }^{5}$

Fleming (1997) characterizes the market for U.S. Treasury securities as "one of the world's largest and most liquid financial markets." Using 1994 data, he estimates that the average daily trading volume in the secondary market was $\$ 125$ billion. Fleming also compares the trading activity by maturity for the most recently issued securities. He estimates that $17 \%$ of the total trading is in the 10-year securities and only $3 \%$ of the total trading is in the 30 -year securities. Accordingly, we choose to report numbers in our tables using the 10-year bond return series. Our results throughout are qualitatively similar using the 30-year bond return series.

For robustness, we also evaluate a return series from the Treasury bond futures contract that is traded on the Chicago Board of Trade. To construct these returns, we use the continuous futures price series from Datastream International. The correlation between the futures returns and our ten-year bond returns is 0.915 over 1986 through 2000. Our empirical results are qualitatively similar when using the futures returns in place of the ten-year bond returns.

For the aggregate stock market return, we use the value-weighted NYSE/AMEX/NASDAQ return from the Center for Research in Security Prices (CRSP). When merging the stock and bond returns, we find that there are a few days when there is not an available yield for the bonds. After deleting these days, we have 3755 observations for each data series.

In our subsequent empirical analysis, we report results using raw returns, rather than excess

\footnotetext{
${ }^{5}$ Studies that consider the impact of Federal Reserve policy and intervention on bond prices include Harvey and Huang (2001) (HH) and Urich and Wachtel (2001) (UW). HH examine the 1982 to 1988 period and find that Fed open market operations are associated with higher bond volatility but that the effect on bond prices is not reliably different for reserve-draining versus reserve-adding operations. UW find that the impact of policy changes on shortterm interest rates have declined in the 1990's since the Fed started making announcements on policy targets.
} 
returns above the risk-free rate. Since we are interested in daily return co-movements, our results are not sensitive to this choice. Using the 3-month T-bill rate for a risk-free rate, the correlation between the raw bond (stock) return and the excess bond (stock) return is 0.999 (0.999). The correlation between the excess stock return and excess bond return is 0.224 , as compared to a 0.223 correlation for the raw returns. Thus, for simplicity, we elect to report results for raw returns.

Table 1, Panel A (Panel B), reports univariate statistics for the data series over the 1986 to 2000 period (the 1988 to 2000 period). Table 1, Panel C, report the simple correlations between the variables. We note that the unconditional correlation between the daily stock and bond returns is modest at around 0.22 to 0.25 , which is quite close to the monthly return correlation reported in Campbell and Ammer (1993).

[Insert Table 1 about here]

Figure 1, Panel A, reports the time-series of 22-trading-day correlations between stock and bond returns, formed from days $t$ to $t+21$. The correlations are calculated assuming the expected daily returns for both stocks and bonds are zero, rather than the sample mean for each 22-day period. This figure illustrates the substantial time-series variation in the stock-bond return relation. Casual inspection of this series indicates a clustering of the periods with a negative correlation. The vast majority of the negative correlations occur from October through December 1987, from October 1989 through February 1993, and from October 1997 through December 2000. Next, Figure 1, Panel B, reports the time-series of the VIX. Eyeball statistics suggest that periods of high VIX and/or increases in VIX are associated with the periods of negative correlation in Panel A.

[Insert Figure 1 about here]

\section{B. Stock Market Turnover}

We also collect daily trading volume and shares outstanding for NYSE/AMEX firms from CRSP over 1986 to 2000. We construct a daily turnover measure for each firm, where turnover is defined as shares traded divided by shares outstanding. Wang (1994) and Lo and Wang (2000) provide a theoretical justification for using turnover instead of other volume metrics. We then calculate the turnover for each size-based, decile portfolios (formed by sorting firms on their stock market capitalization). A portfolio's turnover is defined as the equally-weighted average of the individual firm turnovers for the firms that make-up the portfolio. 
We use the turnover of the largest size-based, decile portfolio in our subsequent empirical work because the large-firm portfolio both approximates the aggregate stock market (in a market capitalization sense) and avoids small-firm concerns (such that high non-synchronous trading or excessive idiosyncratic trading might add noise to a market turnover statistic). For our purposes, large-firm turnover may also be more informative if large-firm trading is more attributed to portfolio re-balancing and less attributed to private information (as compared to small firm turnover). The time-series of our large-firm portfolio's turnover is presented in Figure 1, Panel C.

We then form a de-trended turnover measure in the spirit of Campbell, Grossman, and Wang (1993)(CGW) and Chen, Hong, and Stein (2001). Following closely from CGW, we form our detrended stock turnover at period $t-1$ as follows.

$$
D T V R_{t-1}=\left[\frac{1}{5} \sum_{i=1}^{5} \ln \left(T V R_{t-i}\right)\right]-\left[\frac{1}{245} \sum_{i=6}^{250} \ln \left(T V R_{t-i}\right)\right]
$$

where $\mathrm{TVR}_{t}$ is the average turnover of the firms that comprise our U.S. large-firm portfolio in day $t$. We use a five-day moving average in (1) to remove some of the noise from the turnover series and to avoid day-of-the-week effects. The time-series of $\mathrm{DTVR}_{t-1}$ is presented in Figure 2, Panel A. We assume that DTVR variation is informative about variation in the level of stock market uncertainty, as discussed in Section III.C.

\section{[Insert Figure 2 about here]}

We also need to measure a day's unexpected turnover for our subsequent analysis. To construct a time-series of turnover shocks, we use the procedure and terminology in Connolly and Stivers (2003). Our time-series of turnover shocks is termed the relative turnover (RTO), defined as the residual, $u_{t}$, obtained from estimating the following time-series regression model:

$$
\ln \left(T V R_{t}\right)=\gamma_{0}+\sum_{k=1}^{10} \gamma_{k} \ln \left(T V R_{t-k}\right)+u_{t},
$$

where $\mathrm{TVR}_{t}$ is the turnover for our large-firm portfolio, and the $\gamma$ 's are estimated coefficients. Thus, $\mathrm{RTO}_{t}$ is defined as the unexpected variation in turnover after controlling for the autoregressive properties of turnover. The $\mathrm{R}^{2}$ for model (2) is $67.0 \%$ and the model effectively captures the timetrend in turnover. The estimated coefficients $\gamma_{1}$ through $\gamma_{10}$ are positive and statistically significant for all of the first five lags and eight of the ten. The time-series of $\mathrm{RTO}_{t}$ is presented in Figure 2, Panel B. 


\section{Description of Bond and Stock Return Volatility}

To provide some perspective before proceeding to our principal results, we first provide a brief comparison of the daily volatility in stock and 10-year T-bond returns. For the 1988 to 2000 period, the unconditional daily variance of the stock returns is about four times as large as the unconditional daily variance of the 10-year bond returns. ${ }^{6}$

We also estimate a time-series of conditional volatilities for the stock and bond returns. For this discussion, conditional volatility refers to the conditional standard deviation, estimated by an augmented GARCH(1,1) model that includes the lagged VIX as an explanatory term in the variance equation. ${ }^{7}$ We find that the time-variation in stock conditional volatility is much larger than the time-variation in bond conditional volatility. For our sample, the time-series standard deviation of the bond conditional volatility is only about one-sixth as large as the time-series standard deviation of the stock conditional volatility. Finally, we note that the correlation between the stock volatility series and the bond volatility series is a modest 0.176. When considering cross-market pricing influences, these relative differences suggests that variation in stock market uncertainty (as measured by stock volatility) is likely to be more important than variation in bond market volatility.

\section{Unpredictability of Daily Stock and Bond Returns}

In our primary empirical investigation in the next section, we are interested in the co-movement between the unexpected component of daily bond and stock returns. Accordingly, we should first control for any predictability of returns. However, the expected daily return is tiny compared to the daily volatility and it is common in studies of daily return dynamics to assume the daily expected return is constant (see, e.g., Fleming, Kirby, and Ostdiek (2001).)

To evaluate the predictability issue in our data, we perform the following augmented VAR

\footnotetext{
${ }^{6}$ We report on the 1988 to 2000 period for this comparison to avoid concerns that the October 1987 crash drives our numbers. See Schwert (1989) and Campbell, Lettau, Malkiel, and Xu (2001) for evidence on time-variation in stock market volatility.

${ }^{7}$ We include the VIX as an explanatory variable because prior studies have shown that implied volatility largely subsumes information from lagged return shocks in estimating stock conditional volatility. In our sample, the VIX is not a statistically significant explanatory variable for the bond conditional volatility.
} 
regression on the daily stock and bond returns.

$$
\begin{aligned}
& B_{t}=\alpha_{0}+\alpha_{1} \ln \left(V I X_{t-1}\right)+\alpha_{2} D T V R_{t-1}+\alpha_{3} C r_{t-1}+\sum_{i=1,3} \varphi_{i} B_{t-i}+\sum_{i=1,3} \gamma_{i} S_{t-i}+\varepsilon_{t}^{B} \\
& S_{t}=\beta_{0}+\beta_{1} \ln \left(V I X_{t-1}\right)+\beta_{2} D T V R_{t-1}+\beta_{3} C r_{t-1}+\sum_{i=1,3} \psi_{i} B_{t-i}+\sum_{i=1,3} \phi_{i} S_{t-i}+\varepsilon_{t}^{S}
\end{aligned}
$$

where $B_{t}\left(S_{t}\right)$ is the daily 10-year bond (stock) return, VIX $t_{t-1}$ is the lagged CBOE's Volatility Index, DTVR DT-1 is our lagged, detrended stock turnover from section IV.B, $C r_{t-1}$ is the 22-

trading-day stock-bond return correlation over days $t-1$ to $t-22, \varepsilon_{t}^{B}\left(\varepsilon_{t}^{S}\right)$ is the residual for the bond (stock) return, and the $\alpha_{i}$ 's, $\varphi_{i}{ }^{\prime}$ s, $\gamma_{i}$ 's, $\beta_{i}$ 's, $\psi_{i}$ 's, and $\phi_{i}$ 's are estimated coefficients. The non-return explanatory variables are chosen because these variables are used in the next section to provide information about market conditions when evaluating the stock-bond return relation. Additionally, the lagged VIX term allows the conditional mean return to vary with expected stock market volatility.

We find that (3) and (4) explain very little of the daily bond and stock returns. The $\mathrm{R}^{2}$ of (3) is only $1.01 \%$, and the $\mathrm{R}^{2}$ of (4) is only $1.25 \%$. For the bond return, only the coefficient on the lag-one bond return is positive and statistically significant. For the stock return, only the coefficients on the lag-one bond return and lag-one stock return are positive and statistically significant. The correlation between the raw bond (stock) return and the bond (stock) residual from our augmented VAR is 0.995 (0.994) and the results in our subsequent empirical work are essentially identical whether examining the raw returns or the VAR residuals. Thus, for parsimony and for ease of interpretation of statistics such as the $\mathrm{R}^{2}$, we report results in the subsequent sections for the raw stock and bond returns, rather than for the VAR residuals.

\section{The Stock-Bond Return Relation and Implied Volatility}

In this section, we investigate how the stock-bond return relation varies with VIX. In the first subsection, we examine EQ1 from Section III using two different approaches. Then, in the next subsection, we examine EQ2 from Section III using a day's change-in-VIX as a change-in-uncertainty metric. 


\section{A. Empirical Question 1: With Variation in VIX level}

\section{A.1. Variation in 22-trading-day stock-bond return correlations}

First, in Table 2, we report on the distribution of forward-looking correlations (formed from daily returns over days $t$ to $t+21$ ) following a given VIX value at the end of day $t-1$. For this exercise, we calculate the correlations assuming that the expected daily stock and bond returns are zero (rather than the sample mean from each respective 22-day period). We make this choice because expected daily returns are very close to zero and this choice prevents extreme return realizations from implying large positive or negative expected returns over specific 22-day periods. We choose the 22-trading-day horizon because this horizon corresponds to the maturity of VIX and because many prior studies have formed monthly statistics from days within the month.

[Insert Table 2 about here]

We find that these forward-looking correlations vary negatively and substantially with the VIX level. The unconditional probability of a negative 22-trading-day correlation between stock and bond returns is $15.6 \%$. However, for the days when $\mathrm{VIX}_{t-1}$ is greater than $25 \%$ then the probability of a subsequent negative correlation is $36.5 \%$, which is six times greater than the $6.1 \%$ probability of a negative correlation when $\mathrm{VIX}_{t-1}$ is less than $20 \%$. These probabilities are calculated simply from the occurrence of each outcome in our sample.

For evaluation of the Table 2 results, we calculate a bootstrapped-based distribution for the mean of the 22-trading-day correlations and find that the bootstrapped $1^{\text {st }}$ to $99^{\text {th }}$ percentile range for the mean correlation is 0.3277 to 0.3541 . Thus, the mean of the 22-trading-day correlations for the different VIX conditions in Table 2 are all well outside this inner $98^{\text {th }}$ percentile range. In this study, all of our bootstrapped-based distributions are based on 1000 draws with replacement from the respective sample.

The results are qualitatively similar in one-half subperiods, although the contrast is substantially greater in the second-half subperiod. For the January 1986 to June 1993 period, the unconditional probability of a 22-trading-day negative correlation is only $7.3 \%$. In contrast, for the days when VIX $_{t-1}$ is greater than $35 \%$, then the probability of a subsequent negative correlation is tripled at

22.5\%. For the July 1993 to December 2000 period, the unconditional probability of a 22-tradingday negative correlation is $24.0 \%$. However, for the days when $\operatorname{VIX}_{t-1}$ is greater than $30 \%$, then 
the probability of a subsequent negative correlation is more than tripled at $80.3 \%$. Further, for the second-half subperiod, the probability of a negative correlation is only $2.7 \%$ for the observations when VIX $_{t-1}$ is less than $20 \%$.

In Appendix A, we report on the same analysis as in Table 2 but with stock returns, bond returns, and the implied volatility of equity index options from the German financial markets. The sample period, January 1992 through December 2000, is different due to availability of the German implied volatility. Additionally, we use forward-looking, 33-trading-day correlations for the German analysis because the option maturity for the German implied volatility is 45 calendar days, rather than the 30 calendar days for VIX. For the German financial markets, we also find that a high implied volatility at $t-1$ is associated with a much larger probability for a subsequent negative stock-bond return correlation over periods $t$ to $t+32$. The consistent and strong results in the German market indicate our findings are not unique to the U.S. market.

\section{A.2. Perspective of conditional bond return distributions}

Next, we investigate EQ1 from the perspective of the conditional bond return distribution, given the stock return. Specifically, we are interested in how the $E\left(B_{t} \mid S_{t}\right)$ relation might vary with the lagged VIX (and later our lagged DTVR).

We are interested in the $E\left(B_{t} \mid S_{t}\right)$ (rather than the $E\left(S_{t} \mid B_{t}\right)$ ) because our lagged conditioning variables are assumed to be related to stock market uncertainty (in the sense of the Veronesi papers) or stock market shocks (in the sense of Kodres and Pritsker (2002)). Thus, the focus of our study suggests that we consider the stock uncertainty to have a first-order effect on the stock market and a second-order effect on the bond market. This intuition leads to our focus on the $E\left(B_{t} \mid S_{t}\right)$ relation since we are interested in the stock-to-bond return relation, as depicted in our regression (5) below.

Of course, stock and bond returns are both endogenous variables in the economy and both are jointly determined. Thus, we stress that our investigation here is not from the perspective of a structural economic model, but from the perspective of the conditional distribution of bond returns given the stock return. The estimated coefficients are not meant to imply economic causality but rather document statistical association in return co-movements. ${ }^{8}$

\footnotetext{
${ }^{8}$ Future research along these lines would be enhanced if the specification was based on an asset pricing theory that
} 
If the bivariate distribution of $B_{t}$ and $S_{t}$ was well described by a fixed bivariate normal distribution, then the $E\left(B_{t} \mid S_{t}\right)$ would be just a constant times the observed $S_{t}$ where the constant equals the covariance between $B$ and $S$ divided by the variance of $S$. However, as suggested by our discussion in Section III.A, the expected $B_{t}$ given $S_{t}$ is likely to vary with economic and market conditions.

Our primary interest in this subsection is whether the $E\left(B_{t} \mid S_{t}\right)$ varies with the lagged VIX, as depicted by the following regression:

$$
B_{t}=a_{0}+\left(a_{1}+a_{2} \ln \left(V I X_{t-1}\right)+a_{3} C V_{t-1}\right) S_{t}+\nu_{t}
$$

where $B_{t}$ and $S_{t}$ are the daily 10-year T-bond and stock returns, respectively; $\ln \left(V I X_{t-1}\right)$ is the natural $\log$ of the VIX in period $t-1 ; \nu_{t}$ is the residual, $C V_{t-1}$ is an additional interactive variable explained later, and the $a_{i}$ 's are estimated coefficients. We use the log transformation of VIX to reduce the skewness of the implied volatility series. The primary coefficient of interest is $a_{2}$, which indicates how the stock-to-bond return relation varies with the lagged VIX.

Table 3 reports the results from estimating four variations of (5). First, Table 3, Panel A, reports on a baseline variation of (5) that restricts $a_{2}$ and $a_{3}$ to be zero. As expected, these results indicate an unconditional positive relation between $B_{t}$ and $S_{t}$. The $\mathrm{R}^{2}$ 's are modest at $4.96 \%$ for the entire sample and only $2.06 \%$ for the second-half subperiod.

[Insert Table 3 about here]

Next, Table 3, Panel B, reports on a variation of (5) that restricts $a_{3}$ to be zero. We find that the stock-to-bond return relation varies negatively and very reliably with the lagged VIX. The variation in the stock-bond return relation appears substantial. For example, over the 1988 to 2000 period, the total implied coefficient on $S_{t}$ is 0.360 at the $5^{\text {th }}$ percentile of VIX $t-1$. In contrast, at the 95 th percentile of $\operatorname{VIX}_{t-1}$, the total implied coefficient on $S_{t}$ is essentially zero at 0.012 . Results in other periods are qualitatively similar. The results for the second-half subperiod in column four are especially dramatic. For this period, the total implied coefficient on $S_{t}$ is $0.480(-0.041)$ at the takes into account that stock and bond returns are jointly determined as a function of underlying state variables, see, e.g., Bekaert and Grenadier (2001) and Mamaysky (2002). However, existing theory does not suggest an obvious specification from which to empirically examine time-variation in daily stock-bond return dynamics. Here, we examine a simple specification that describes one aspect of stock and bond return co-movements, while acknowledging the limitations of our regression specification. 
VIX's $5^{t h}\left(95^{t h}\right)$ percentile. Also note the substantial increases in $\mathrm{R}^{2}$ for the results in Panel B as compared to Panel A. For the second-half subperiod, the $\mathrm{R}^{2}$ increases from about $2 \%$ in Panel A to nearly $15 \%$ in Panel B with the lagged VIX information.

For comparison to these VIX-based variations in the total implied coefficient on $S_{t}$, we calculate bootstrap-based distributions of the $a_{1}$ coefficient for the baseline model variation in Panel A over all four sample periods. The implied total coefficients on $S_{t}$ at the VIX's $95^{\text {th }}$ and $5^{t h}$ percentile in Table 3, Panel B, are all outside the respective inner $90^{\text {th }}$ percentile range for the the $a_{1}$ coefficient except for the VIX-95 $5^{t h}$-percentile estimate for the first-half subperiod. This comparison further suggests that the VIX-based variations are substantial and statistically significant.

Table 3, Panel C, reports results on the case where $C V_{t-1}$ is the lagged correlation between the stock and bond returns from period $t-1$ to $t-22$. This variation of $(5)$ is meant to evaluate whether the lagged VIX provides incremental information about the stock-to-bond return relation, beyond the information in the recent historical correlation. For all four periods in Table 3, we find that the negative relation between lagged VIX and the $E\left(B_{t} \mid S_{t}\right)$ relation remains very reliably evident, even when directly considering the information from recent stock-bond return correlations. The estimated $a_{3}$ coefficient is positive and significant for the overall sample and for two of the three subperiods, so there does tend to also be information from the lagged rolling-correlation estimates.

Next, Figure 1, Panel A, indicates strong and persistent negative stock-bond correlations in late 1997 and the second half of 1998. These observations suggest that the Asian financial crisis of 1997 and the Russian financial crisis of 1998 may be particularly influential in our results. The variation of (5) in Table 3, Panel $\mathrm{D}$, addresses this issue. For this case, $C V_{t-1}$ equals one during the Asian crisis and/or the Russian crisis, and equals zero otherwise. We use the crises dates from Chordia, Sarkar, and Subrahmanyam (2001) (October 1, 1997 through December 31, 1997 for the Asian crisis and July 6, 1998 through December 31, 1998 for the Russian crisis).

We note that this variation of (5) is different because now this interactive variable uses ex post information, rather than only lagged information (as in Panel B and C). We find that the estimated $a_{3}$ on the $C V_{t-1}$ variable is negative and highly statistically significant for both crises, both jointly and individually. However, the estimated $a_{2}$ for the interactive VIX term also remains negative and highly statistically significant. The statistical significance of $a_{2}$ even increases in the Panel D case, as compared to the Panel B case. We also extend our crises variable to include the Persian 
Gulf war (August 1990 through February 1991) and find nearly the same result for the estimated $a_{2}$ coefficient. Thus, the lagged VIX relation remains strong even when directly controlling for these crisis period using ex post information.

We also run the tests in Table 3 in a GARCH system where the mean equation is given by equation (5) and with the following conditional variance equation.

$$
h_{t}=\gamma_{0}+\gamma_{1} \nu_{t-1}^{2}+\gamma_{2} h_{t-1}+\gamma_{3} V I X_{t-1}
$$

where $h_{t}$ is the conditional variance, the $\gamma_{i}$ 's are estimated coefficients, and the other terms are as defined for (5). We estimate this GARCH system by maximum likelihood using the conditional normal density and use Bollerslev and Wooldridge (1992) standard errors that are robust to departures from conditional normality. The results are qualitatively and quantitatively similar to the OLS results in Table 3 and the $\gamma_{3}$ coefficient on the lagged VIX is statistically insignificant. We conclude that our results are robust to allowing for conditional heteroskedasticity.

\section{B. Empirical Question 2: With the Daily VIX Change}

It has been documented that stock returns are negatively and reliably associated with contemporaneous changes in VIX, see Fleming, Ostdiek, and Whaley (1995). However, the issue of whether bond returns are related to changes in VIX has not been explored. In Table 4, we report on this issue by sorting observations on their change-in-VIX and then calculating subsample statistics for the different change-in-VIX groupings.

[Insert Table 4 about here]

These results suggest that the correlation between stock and bond returns decrease during periods with substantial VIX increases. For the top five (25) percentile of VIX increases, the correlation is $-0.055(0.112)$, in contrast to the 0.223 unconditional correlation. Further, our results suggest that T-bond returns are large, relative to stocks, during periods of very large VIX increases. For example, for the largest five percentile of VIX increases, the average daily stock return is over two stock-return standard deviations below the unconditional stock mean. In contrast, for the largest five percentile of VIX increases, the average daily bond return is only about one-sixth of a bond-return standard deviation below the unconditional bond mean (this stock-bond return comovement during the periods with large VIX increases is only $36 \%$ as large as that predicted by the 
unconditional correlation). These findings seem consistent with the idea of cross-market hedging (or flight-to-quality) during periods when stock market uncertainty increases substantially.

\section{The Stock-Bond Return Relation and Stock Turnover}

In this section, we investigate how the stock-bond return relation varies with stock turnover. We perform the same battery of tests as in the preceding section, but here we use our stock turnover measures rather than VIX.

\section{A. Empirical Question 1: With Variation in Detrended Stock Turnover}

\section{A.1. Variation in 22-trading-day stock-bond return correlations}

In Table 5, we report on the distribution of forward-looking correlations (formed from daily returns over days $t$ to $t+21$ ) following a given $\mathrm{DTVR}_{t}-1$ value. Recall that DTVR is our detrended turnover measure as described in Section IV.B. As before, we calculate the correlations assuming that the expected daily stock and bond returns are zero.

[Insert Table 5 about here]

Our results indicate that these forward-looking correlations vary negatively and substantially with the DTVR D $_{t-1}$ level. When $\mathrm{DTVR}_{t-1}$ is greater than its $90^{t h}$ percentile, then there is a $34.2 \%$ chance of observing a subsequent negative correlation between stock and bond returns over the next

month. However, when DTVR ${ }_{t-1}$ is less than its $25^{\text {th }}$ percentile, then there is only a $11.7 \%$ chance of observing a subsequent negative correlation between stock and bond returns. Further, the mean of the 22-trading-day correlations for the different DTVR conditions in Table 5 are all outside the inner $98^{\text {th }}$ percentile range of the bootstrap-based distribution for the mean of the 22-trading-day correlations over our entire sample.

This qualitative comparison is also consistent in one-half subperiods, although the contrast is substantially greater in the second-half subperiod. For the first-half subperiod, the unconditional probability of a 22-trading-day negative correlation is only $7.3 \%$. In contrast, for the days when $\mathrm{DTVR}_{t-1}$ is greater than its $90^{t h}$ percentile, the probability of a subsequent negative correlation is doubled at $14.4 \%$. For the second-half subperiod, the unconditional probability of a 22-trading-day 
negative correlation is $24.0 \%$. For the days when $\mathrm{DTVR}_{t-1}$ is greater than its $90^{\text {th }}$ percentile, the probability of a subsequent negative correlation is more than doubled at $51.3 \%$.

\section{A.2. Perspective of conditional bond return distributions}

Here, we estimate the following regression to further investigate variation in the stock-to-bond return relation associated with the lagged detrended stock turnover. Our perspective and the intuition behind this regression is the same as in Section V.A.2. for the comparable VIX regression.

$$
B_{t}=a_{0}+\left(a_{1}+a_{2} D T V R_{t-1}+a_{3} C V_{t-1}\right) S_{t}+\nu_{t}
$$

where $D T V R_{t-1}$ is our lagged detrended stock turnover as defined in section IV.B, and the other terms are as defined for (5). The primary coefficient of interest is $a_{2}$, which indicates how the stock-to-bond return relation varies with the lagged DTVR.

Table 6, Panel A, reports on the simple variation of (7) with no interactive variables. The results are described in Section V.A.2. Next, Table 6, Panel B, reports results on the variation of (7) with only the DTVR information (restricts $a_{3}$ to be zero). We find that the stock-bond return relation varies negatively and very reliably with the lagged DTVR. At the 5 th percentile of $\mathrm{DTVR}_{t-1}$, the total implied coefficient on $S_{t}$ is substantial at a value of 0.215 . In contrast, at the 95th percentile of the lagged DTVR, the total implied coefficient on $S_{t}$ is only 0.051. Subperiod results are similar.

[Insert Table 6 about here]

We also compare the DTVR-implied coefficients $\left(a_{1}+a_{2} * D T V R\right.$ value $)$ to bootstrap-based distribution of the $a_{1}$ coefficient for the baseline case in Panel A. The implied total coefficients on $S_{t}$ at the DTVR's $95^{t h}$ and $5^{\text {th }}$ percentile are all outside the respective inner $90^{\text {th }}$ percentile range of the bootstrap-based distribution for $a_{1}$.

Table 6, Panel $\mathrm{C}$, reports on the case where $C V_{t-1}$ equals the lagged correlation between the stock and bond returns from period $t-1$ to $t-22$. Our estimation indicates the following. First, for the overall sample, the estimated $a_{2}$ remains negative and highly statistically significant. For the subperiods, the estimated $a_{2}$ remains negative, but it is insignificant in two of the subperiods. The estimated $a_{3}$ coefficient is positive and significant for all periods except $1 / 86-12 / 93$, so there does tend to be information from the lagged rolling-correlation estimates.

Finally, Table 6 , Panel D, reports on the case where $C V_{t-1}$ equal one during the Asian crisis 
and/or the Russian crisis, and equals zero otherwise. (See the details in Section V when describing the comparable VIX model.) We find that the estimated $a_{2}$ on the lagged DTVR variable remains negative and highly statistically significant. Thus, the lagged DTVR relation also remains strong even when directly controlling for these crises using ex post information.

As we did in Section V.A.2, we also estimate the relation in (7) within a GARCH system where the mean equation is given by (7) and the conditional variance equation is given by (6), except that DTVR replaces the VIX term. The results are qualitatively and quantitatively similar to the OLS results in Table 6 and the DTVR term is not reliably related to the bond conditional volatility. We conclude that the DTVR results are robust to allowing for conditional heteroskedasticity.

\section{B. Empirical Question 2: With Unexpected Stock Turnover}

Finally, we examine how the co-movement between stock and bond returns varies with the contemporaneous unexpected turnover in the stock market. In addition to the notion that turnover is associated with diverse beliefs and uncertainty (see Section III.C), it also seems likely that high turnover would be associated with periods of substantial changes in cross-market hedges and portfolio rebalancing. We use our RTO measure, as described in Section IV.B, to measure the turnover shock. Table 7 reports the results.

\section{[Insert Table 7 about here]}

We find that the mean bond return increases nearly monotonically with the unexpected turnover. For example, for the under- $5^{\text {th }}$ (under- $25^{\text {th }}$ ) percentile RTO days, the mean bond return is negative at $-0.028 \%(-0.009 \%)$. In contrast, for the above- $95^{\text {th }}$ (above- $75^{\text {th }}$ ) percentile RTO days, the mean bond return is positive at $0.115 \%(0.099 \%)$. The difference between the mean bond return of the under- $5^{\text {th }}$ and above- $95^{\text {th }}$ (under- $25^{\text {th }}$ and above- $75^{\text {th }}$ ) percentile RTO days is statistically significant at a p-value of $1.3 \%(<1 \%)$. Further, the mean bond return for the above- $95^{\text {th }}$ percentile RTO days is over four times the unconditional mean of the bond return. These findings also suggest that cross-market pricing influences have an appreciable effect on bond returns.

In contrast, none of the mean stock returns across the RTO subsamples are significantly different than the unconditional mean stock return. However, during periods of extremely high unexpected stock turnover, the average stock returns are low, relative to the average bond returns. For the above- $95^{\text {th }}$ percentile RTO days, the average stock return is below its unconditional average at 
$0.044 \%$ and the average bond return is much higher than its unconditional average at $0.113 \%$ (numbers are for the sample excluding the October 19, $1987 \mathrm{crash}$ ).

\section{Regime-shifting Analysis}

\section{A. Models of Regime Switching in the Stock-Bond Return Correlation}

To this point, our empirical investigation has produced new evidence that links the stock-bond return relation to both the relative level and changes in VIX and stock turnover. Our findings provide strong support for a "Yes" answer to our primary empirical questions discussed in Section III. Further, we have shown that VIX and stock turnover continue to provide reliable information about the stock-bond return relation even when directly controlling for lagged, rolling correlations and major international financial crises.

In this section, we explore a regime-shifting approach to modeling these shifts in the stockbond return relation. There is considerable evidence of regime switching in both stock and bond returns. ${ }^{9}$ Our purpose in this section is three-fold: (1) to show that a simple regime-switching model also picks up statistically reliable time-variation in the stock-bond return relation, (2) to show that the probability of switching from one regime to another depends on the lagged VIX and our lagged DTVR in a manner consistent with our findings in Sections V and VI, and (3) to show that inflation behavior exhibits little variation across the regimes. Our regime-shifting analysis also has implications for asset allocation between stocks and bonds.

To provide a simple initial benchmark, we first estimate a basic two-state regime-switching model given by

$$
B_{t}=a_{0}^{s}+a_{1} B_{t-1}+a_{2}^{s} S_{t}+\epsilon_{t}
$$

\footnotetext{
${ }^{9}$ As Engel and Hamilton (1990) point out, even simple versions of these models are capable of capturing a wide variety of time-series dynamics. Since regime-switching models are well established in the literature, we provide only a quick sketch of the method. See Hamilton (1994) for an overview. Gray (1996) is a seminal application of regime-switching methods to short-term yields. Boudoukh, Richardson, Smith, and Whitelaw (1999) argue that bond returns display behavior consistent with regime switching. Kim and Nelson (2001) provide an excellent discussion of regime-switching models and their application to bond and stock returns. Ang and Bekaert (2002a, b) explore the use of regime-switching models in bond pricing. Also, see Whitelaw (2000) and the earlier-cited Veronesi papers for other important explorations of regime-switching in financial economics.
} 
where $B_{t}$ and $S_{t}$ are the daily T-bond and stock returns, respectively; $\epsilon_{t}$ is the residual; and the $a$ 's are estimated coefficients. The superscript $s$ indicates regime 0 or regime 1 , where $s$ can be regarded as an unobserved state variable that follows a two-state, first-order Markov process. The transition probability matrix can be written as follows:

$$
\mathbf{X}=\left(\begin{array}{cc}
p & 1-p \\
1-q & q
\end{array}\right)
$$

where $p=\operatorname{Pr}\left(s_{t}=0 \mid s_{t-1}=0\right)$, and $q=\operatorname{Pr}\left(s_{t}=1 \mid s_{t-1}=1\right)$. We refer to this model subsequently as the constant transition probability regime-switching (CTP-RS) model. Our discussion in Section V.A.2 explains why we estimate this model with the bond return as the dependent variable and the stock return as an explanatory variable, rather than vice versa.

If the stock-bond return relation is persistently positive and then persistently negative, we expect $a_{2}^{0}$ and $a_{2}^{1}$ to have opposite signs and both $p$ and $q$ to be large. This is strongly contrasted by the case where the stock-bond return relation in a period is independent of the relation in the previous period. If this holds, we expect $1-p$ to be equal to $q$.

We also estimate a more sophisticated regime-switching model with time-varying transition probabilities in order to address the fundamental question: Does the probability of switching vary significantly with lagged VIX (or our lagged DTVR)? Specifically, instead of constraining the $p$ and $q$ to be constants, we follow Diebold et al. (1994), and specify time-varying transition probabilities as follows:

$$
p\left(s_{t}=j \mid s_{t-1}=j ; I_{t-1}\right)=\frac{e^{c_{j}+d_{j} \ln \left(V I X_{t-1}\right)}}{1+e^{c_{j}+d_{j} \ln \left(V I X_{t-1}\right)}}, j=0,1 .
$$

We refer to this model as the time-varying transition probability regime-switching (TVTP-RS) model. This model specification encompasses our CTP-RS model. We later test directly for the superiority of this TVTP-RS model over our simpler CTP-RS model, where the null hypothesis is that the probability of shifting from one regime to another is not related to the lagged VIX (DTVR).

For our regime-shifting estimation, we elect to not model heteroskedasticity in the bond returns for parsimony and the following reasons. First, time-variation in bond return volatility is much smaller than time-variation in stock return volatility. Second, the correlation between time-varying 
stock volatility and time-varying bond volatility is modest. Finally, the lagged VIX is not reliably related to time-varying bond volatility.

\section{B. Empirical Results}

In Table 8, we report on our CTP-RS model, estimated on the 10-year Treasury bond returns over both the 1986 to 2000 period and the 1988 to 2000 period. The results are similar for both periods. To summarize, we find strong evidence of regime-shifting behavior with substantial contrast between the regimes. The estimated $p$ and $q$ probabilities are large (near one), indicating persistent regimes. In the first regime (denoted regime-zero in the table), we find that the $a_{2}^{0}$ coefficient on stock returns is large and statistically significant at a value of 0.304. In contrast, in the second regime (denoted regime-one in the table), we find that the $a_{2}^{1}$ coefficient on stock returns is negative and statistically significant at a value of -0.050 .

\section{[Insert Table 8 about here]}

Figure 3 displays the regime-shifting behavior. In Figure 3, the upper series is the VIX and the lower series is the smoothed probability of being in regime-one for the 10-year T-bond returns. Note the close mapping between the periods with negative correlation in Figure 1, Panel A, and the regime-one periods in Figure 3.

\section{[Insert Figure 3 about here]}

We also compare the stock and bond average returns, volatility, and correlations across the two regimes. Table 8, Panel B, reports results for the 10-year T-bonds, over both the 1986 to 2000 period and the 1988 to 2000 period. We categorize an observation as belonging to a particular regime if there is at least an $80 \%$ probability of the observation being in the particular regime. This comparison indicates the following. First, regime-zero comprises about two-thirds of the daily observations. In regime-zero, the correlation between the stock and bond returns is quite high at 0.52 , average stock returns are high (relative to the bond returns), and stock volatility is modest. Second, regime-one comprises less than one-fourth of the observations. For regime-one, the correlation between the stock and bond returns is much lower than normal at about -0.20 , average bond returns are high (relative to stock returns), and stock volatility is much higher than normal. Finally, bond volatility does not vary substantially across the regimes, which supports our choice to not model bond heteroskedasticity. These differences across regimes suggest a "relatively 
normal, lower uncertainty" regime versus a "relatively abnormal, higher uncertainty" regime. ${ }^{10}$

Next, in Table 9, we report our results for the TVTP-RS model, estimated over 1988 to $2000{ }^{11}$ The regime behavior and the estimated $a_{i}^{j}$ coefficients are similar to those for the CTP-RS model in Table 8. For the transition probabilities in the TVTP-RS model, we note that the estimated $d_{0}$ is significantly negative. This indicates that a high $V I X_{t-1}$ will lower the probability of staying in regime zero. For regime-one, the estimated $d_{1}$ is positive (but statistically insignificant), which suggests that a high $V I X_{t-1}$ may increase the probability of staying in regime one. Both the TVTPRS model and the CTP-RS model confirm the presence of statistically-significant regime-shifting in the stock-bond return relation.

[Insert Table 9 about here]

We perform a likelihood ratio test that compares our CTP-RS model to our TVTP-RS model. This test indicates that the estimated $d_{0}$ and $d_{1}$ are jointly statistically significant with a p-value $<$ 0.001, which rejects the CTP-RS model in favor of the TVTP-RS model. This result also suggests that stock market uncertainty plays a functional role in explaining the dynamics of the stock-bond return relation.

Table 9, Panel B, reports basic descriptive statistics for the return observations in each regime for the TVTP-RS model. Figure 4 presents the relation between VIX movements and the regimes graphically. The comparison of return statistics across regimes is very similar to that for the CTPRS model, but the regimes exhibit less persistent. The difference in correlations across regimes is even greater at 0.950 for our TVTP-RS model versus 0.767 for our CTP-RS model.

[Insert Figure 4 about here]

For both our CTP-RS and TVTP-RS model, the regime-one behavior primarily falls into the three subperiods of $10 / 87$ to $12 / 87,10 / 89$ to $2 / 93$, and $10 / 97$ to $12 / 00$. The remainder of the months

\footnotetext{
${ }^{10} \mathrm{~A}$ few observations are not clearly classified in either regime. We also calculate the statistics for the different regimes for the $1 / 86$ - 6/93 and $7 / 93$ - 12/00 subperiods. For the first half, the stock-bond correlation is 0.501 (0.131) for regime-zero (regime-one), which encompasses 1347 (208) observations. For the second half, the stock-bond correlation is 0.551 (-0.239) for regime-zero (regime-one), which encompasses 1177 (621) observations.

${ }^{11}$ For the TVTP-RS model, we formally report results for the 1988 to 2000 period only. We made this choice due to econometric concerns related to the extreme VIX around the October 1987 crash. However, we also estimate the TVTP-RS model for the entire 1986-2000 period. The regime-shifting behavior is very similar to that depicted in Table 9 but the coefficients are less precisely estimated.
} 
can be categorized as predominantly regime-zero. We use this approximate regime breakdown in our examination of inflation below.

Recall that Campbell and Ammer's (1993) fundamental approach suggests that only movements in inflation should induce a negative correlation between stock and bond returns. Thus, we examine whether inflation behavior varies across the regimes. For inflation, we evaluate monthly changes in the seasonally-adjusted Consumer Price Index. For the regime-zero months, the average inflation was $0.250 \%$ per month and the inflation volatility was $0.144 \%$ per month (proxied for by the average absolute change in the monthly inflation rate). For the regime-one months, the average inflation was $0.270 \%$ per month and the inflation volatility was $0.162 \%$ per month. These inflation differences across the regimes seem modest and are not statistically significant. Thus, this comparison further suggests that inflation is not the primary factor behind our results.

Finally, we also investigate whether the lagged DTVR is useful in modeling the transition probabilities in our TVTP-RS regime-shifting model, where DTVR replaces the VIX term. The regime behavior is qualitatively similar to the results in Table 9 for the VIX model, except that the $d_{j}$ coefficients on the DTVR terms are less precisely estimated. As for the VIX model, the estimated $d_{0}$ is negative and the estimated $d_{1}$ is positive. However, for the DTVR, both the $d_{j}$ coefficients are statistically insignificant.

\section{Duration of Regimes and Portfolio Management}

The transition probability estimates provide some additional insights into the implications of the regime-switching for portfolio management. We explore these issues briefly in this subsection. Since our testing rejects the CTP-RS model in favor of the TVTP-RS VIX model, we focus on the TVTP-RS model here.

In the TVTP-RS model, the estimated duration depends on the value of VIX (where the expected duration of regime $i$ is: $\left.E(D)=\frac{1}{1-p_{i i}}, p_{i i}=\operatorname{Pr}\left(s_{t}=i \mid s_{t-1}=i\right)\right)$. Evaluating our TVTP-RS model at a $V I X_{t-1}$ value of $15 \%$, the expected duration of staying in regime zero is 53 days. When $V I X_{t-1}$ is $30 \%$, the expected duration of staying in regime zero falls to only 16 days. The expected durations for regime one are 13 days (when $V I X_{t-1}$ is $15 \%$ ) and 34 days (when $V I X_{t-1}$ is $30 \%$ ). The length of these durations and the variability of the durations with the lagged VIX may be of interest to portfolio managers who are trying to maximize performance metrics such as the Sharpe 
ratio. In this respect, our investigation may be extended and linked with research by Ang and Bekaert (2002c) into the consequences of regimes for asset allocation.

\section{Conclusions}

We study daily stock and bond returns over 1986 to 2000 and examine whether non-return-based measures of stock market uncertainty can be linked to variations in the stock-bond return relation. Particularly intriguing are the periods of sustained negative correlation between daily stock and bond returns, which contrasts with the overall modest positive correlation. Since there is little difference in inflation behavior over our sample period, it seems unlikely that differences in inflation are behind the time-variation in the stock-bond return relation. Our empirical investigation assumes that the time-series behavior of the implied volatility from equity index options and of detrended stock turnover is informative about variation in stock market uncertainty.

First, from a forward-looking perspective, we find a negative relation between our uncertainty measures and the future correlation between stock and bond returns. The probability of a negative correlation between daily stock and bond returns over the next month is several times greater following relatively high values of IV and DTVR. In Appendix A, we document similar time-varying correlations when analyzing stock returns, government bond returns, and the implied volatility of equity index options from the German financial markets over the 1992 to 2000 period. Second, from a contemporaneous focus, we find that bond returns tend to be high (low), relative to stock returns,

during days when IV increases (decreases) substantially and during days when stock turnover is unexpectedly high (low). Finally, we also investigate a two-state regime-shifting approach to modeling time-variation in the stock-bond return relation and find that: (1) the estimation indicates sharply defined regimes where the stock-bond return relation is either substantially positive or modestly negative, (2) the probability of switching from one regime to another depends on the lagged VIX and our lagged detrended stock turnover in a manner consistent with our other findings, and (3) inflation behavior exhibits little variation across the regimes.

Collectively, our results suggest that stock market uncertainty may generate important crossmarket pricing influences, as suggested in Fleming, Kirby, and Ostdiek (1998), Kodres and Pritzker (2002), and Chordia, Sarkar, and Subrahmanyam (2001). Our findings also suggest that stock 
implied volatility and detrended stock turnover may be useful as state variables that are informative about economic uncertainty in the sense of Veronesi (1999) and (2001), and David and Veronesi (2002). Further, our findings suggest that times of high stock uncertainty are also times with more frequent revisions in investors' assessments of both stock risk and the relative attractiveness of stocks versus bonds. If so, this dynamic behavior seems capable of explaining periods of negative correlation in stable inflationary times.

An interesting question is whether the time-variation in the stock-bond return relation is more of an international phenomenon or a country-specific phenomenon. In Appendix B, we take an initial look at this question by examining whether the stock-bond return correlation in the other G-7 countries varies across the regimes suggested by our U.S. results. We find that each country's stock-bond return correlation varies similarly and significantly across the U.S. regimes, except for Japan. For example, the U.K.'s stock-bond return correlation is 0.467 during the U.S.'s "primarily regime-zero months" versus only 0.078 during the U.S.'s "substantially regime-one months". These findings suggest an international aspect to our findings.

Another interesting question is whether the behavior of mutual fund flows varies across our regimes from Section VII. Cross-market pricing influences associated with stock market uncertainty seem likely to also be reflected in fund flow behavior. As previously noted, Chordia, Sarkar, and Subrahmanyam (CSS) (2001) examine the 1991 to 1998 period and find evidence that net equityfund flows decreased and net government-bond-fund flows increased during the 1997 Asian crisis and 1998 Russian crisis. In Appendix C, we also examine monthly fund flows but expand the analysis from 1986 to 2000. Consistent with CSS, we find evidence that stock (bond) fund redemptions are higher (lower) in our regime-one, as compared to our regime-zero.

Finally, it is an interesting empirical question whether longer horizon returns (such as monthly) exhibit patterns that are qualitatively similar to our principal daily-return findings. The answer seems likely to depend upon the underlying economics for our findings. For example, if short-lived financial crises (such as the 1998 Russian financial crisis) are of fundamental importance to our daily results, then similar patterns might not be reliably evident in monthly returns. On the other hand, if stock market uncertainty is more related to longer-term variations in economic conditions, then it seems likely that similar patterns would be reliably evident in monthly returns. Regardless, it seems likely that the magnitude and reliability of the time-variations would be less for longer 
horizon returns since: (1) fewer observations are available for measuring time-varying correlations, and (2) the specification of expected returns becomes important for longer-horizon returns, which would complicate the empirical testing and interpretation. In our study, we are limited in what we can say about monthly returns since VIX is not available until 1986. We do estimate the regression from Table 3 with monthly returns and find qualitatively similar time-variation in the stock-bond monthly return co-movements as a function of lagged VIX. ${ }^{12}$

From a practical perspective, our results may have direct financial applications. Specifically, the implied volatility from equity-index options and stock turnover may be useful for financial applications that need to understand and predict stock and bond return co-movements. For example, our findings imply that joint stock-bond return models should allow for the return correlation to vary and suggest that our uncertainty variables may be useful in modeling this variation. Further, our findings suggest increased diversification benefits for portfolios of stocks and bonds during periods of high stock market uncertainty. Such a timely diversification benefit is in contrast to cross-equity market international diversification, where much of the literature (see, e.g., King and Wadhwani (1990) and Lee and Kim (1993)) has argued that cross-country stock returns may be more positively linked during times of high uncertainty. Future research to better pinpoint the theoretical and practical implications of our findings should prove interesting.

\footnotetext{
${ }^{12}$ We estimate our regression (5) with 22-trading-day overlapping returns as monthly returns and with $a_{3}$ restricted to zero.
} 


\section{Appendix}

\section{A. German Stock-Bond Return Correlation and Stock Implied Volatility}

Here we briefly describe how the correlation of daily German stock and bond returns varies with the implied volatility from German equity index options (the VDAX). The VDAX is derived from options on the DAX equity index, in a manner similar to the U.S. VIX. However, the VDAX has a 45-calendar-day horizon, rather than the 30-calendar-day horizon of the U.S. VIX. The sample period covers 1992 to 2000 due to VDAX data availability.

We calculate daily stock and bond returns for Germany using the DataStream International total return indices for the German equity market and the German benchmark bond (series TOTMKBD(RI) and BMBD10Y(RI)). To measure variation in the stock-bond return correlation, we split the sample based on values for the VDAX measure and calculate the stock-bond return correlation for observations meeting the sample criterion. For a given VDAX observation at day t-1, the subsequent correlation is calculated using returns over days $t$ to $t+32$. The results are summarized below:

\begin{tabular}{lcccccc} 
VDAX Criterion & Obs. & \% Corr. $<0$ & Mean & Median & $25^{\text {th }}$ Pctl. & $75^{\text {th }}$ Pctl. \\
\hline All & 2270 & $15.5 \%$ & 0.346 & 0.392 & 0.177 & 0.591 \\
$0-25^{\text {th }}$ pctl. & 575 & $0.0 \%$ & 0.532 & 0.551 & 0.392 & 0.661 \\
$25^{\text {th }}-50^{\text {th }}$ pctl. & 576 & $0.3 \%$ & 0.477 & 0.504 & 0.339 & 0.647 \\
$50^{\text {th }}-75^{\text {th }}$ pctl. & 549 & $18.8 \%$ & 0.297 & 0.324 & 0.058 & 0.586 \\
$75^{\text {th }}-95^{\text {th }}$ pctl. & 454 & $37.8 \%$ & 0.091 & 0.183 & -0.176 & 0.321 \\
$90^{\text {th }}-100^{\text {th }}$ pctl. & 232 & $52.2 \%$ & 0.041 & -0.013 & -0.158 & 0.313 \\
\hline
\end{tabular}

These results indicates the same negative relationship between the level of implied volatility and the subsequent stock-bond return correlation. This suggests a generality to our U.S. results.

\section{B. Stock-Bond Correlations in Other Countries across U.S. Regimes}

As we note in our conclusions, it is an interesting question whether the time-variation in the stock-bond return correlation is more of a general phenomenon or a country-specific finding. In this appendix, we examine whether the stock-bond return correlation in the other G-7 countries (Canada, France, Germany, Italy, Japan, and the U.K.) varies across the regimes suggested by our U.S. results (see Section VII, Table 8, and Figure 3).

The daily international stock and bond data used to calculate return correlations are all from DataStream International. The individual stock series, bond series, (with the DataStream code in parentheses) and the sample start for each country are as follows: Canada: Toronto SE 35 (TTSEI35), Canada Benchmark Bond 10 Yr. (CNBRYLD), 8/19/88; France: France CAC 40 (FRCAC40), France Benchmark Bond 10 Yr. (FRBRYLD), 7/9/87; Germany: DAX 30 (DAXINDZ), Germany Benchmark Bond 10 Yr. (BDBRYLD), 1/1/86; Italy: Milan COMIT 30 (MIBCI3Z), Italy Benchmark Bond 10 Yr. (ITBRYLD), 3/6/91; Japan: Nikkei 225 Stock Average (JAPDOWA), Japan Benchmark Bond 10 Yr (JPBRYLD), 1/1/86; U.K.: FTSE 
100 (FTSE100), UK Benchmark Bond 10 Yr. (UKMBRYD), 5/15/86. The sample periods vary somewhat among these countries owing to different data availability.

Means and standard deviations for the bond and stock return series for each country are reported below. Here, separate statistics are reported for the "primarily regime-zero" months and the "primarily regime-one" months, where the classification is as suggested in Figure 3 and are the same that we use in our inflation comparison across regimes in Section VII. The "primarily regime-one" months are from 10/87 to 12/87, $10 / 89$ to $2 / 93$, and $10 / 97$ to $12 / 00$. The remainder of the months are classified as "primarily regime-zero". This table reflects two patterns. First, stock return volatility substantially exceeds bond return volatility for each country. Second, while the standard deviation of bond returns is stable across the two regimes, stock return volatility rises considerably from regime-zero to regime-one. That is, foreign country stocks tend to be riskier in regime-one, but foreign bond risk is essentially unchanged. This pattern is similar to that observed in the U.S. data.

\begin{tabular}{cccccccc} 
Regime & Country: & Canada & France & Germany & Italy & Japan & U.K. \\
\hline \multirow{7}{*}{ Regime 0 } & Meanel A: Bond Returns & 0.0343 & 0.0291 & 0.018 & 0.0657 & 0.0208 & 0.022 \\
& Std. Dev & 0.4885 & 0.3953 & 0.3457 & 0.5946 & 0.452 & 0.4575 \\
\multirow{2}{*}{ Regime 1 } & Mean & 0.032 & 0.029 & 0.0241 & 0.0316 & 0.0214 & 0.0412 \\
& Std. Dev & 0.4325 & 0.4505 & 0.3397 & 0.3922 & 0.3992 & 0.4503 \\
& & & & & & & \\
Regime 0 & Mean & 0.0617 & 0.0657 & 0.0619 & 0.0719 & 0.0648 & 0.0676 \\
& Std. Dev & 0.6732 & 1.0127 & 1.0802 & 1.3545 & 1.0759 & 0.7417 \\
Regime 1 & Mean & 0.022 & 0.0297 & 0.0116 & 0.0599 & -0.0523 & 0.0109 \\
& Std. Dev & 1.0128 & 1.4398 & 1.541 & 1.5433 & 1.6551 & 1.1885 \\
\hline
\end{tabular}

With this data, we also compute stock-bond return correlations using daily data for each country for each regime (we include the full sample correlation for comparison). The results are reported below.

Stock-Bond Return Correlations

\begin{tabular}{lcccccc} 
Country: & Canada & France & Germany & Italy & Japan & U.K. \\
\hline Regime & & & & & & \\
Full & 0.181 & 0.29 & 0.227 & 0.292 & 0.026 & 0.232 \\
Regime 0 & 0.378 & 0.444 & 0.361 & 0.453 & -0.013 & 0.467 \\
Regime 1 & 0.048 & 0.202 & 0.123 & 0.128 & 0.061 & 0.078 \\
Difference & $0.330^{*}$ & $0.242^{*}$ & $0.238^{*}$ & $0.325^{*}$ & -0.074 & $0.389^{*}$ \\
\hline
\end{tabular}

\footnotetext{
* indicates statistically significant at a p-value of less than $1 \%$.
} 
Rather than relying on normal distribution theory to test for differences in correlation, we apply bootstrap methods to each sample and construct the distribution of differences in estimated correlations across the bootstrap replications. We then base our inferences about significant differences in correlation across different regimes on the bootstrap-based distribution of differences. Underlying deviations from normality should have no significant impact on the inferences using this method. The specific steps are as follows. First, we resample the data from each regime and construct 1000 estimates of the stock-bond return correlation. Second, we construct densities of the differences in correlations (sample size $=1000$ ) and test whether the mean of the difference is zero using the empirical distribution.

Except for Japan, the differences in the correlations are statistically significant at the one per cent level (or better) in every case. The size of the differences for Canada and the U.K. approach the magnitudes in the U.S. data. We conclude that our primary findings for the U.S. are largely mirrored in the other countries, which suggests an international aspect to our findings.

\section{Mutual Fund Flows across U.S. Regimes}

In this appendix, we examine aggregate mutual fund flows over the 1986 to 2000 period. Specifically, we are interested in whether the fund flow behavior varies across our regimes from Section VII. We use the same monthly regime categorization as reported in Appendix B and Section VII for the inflation comparison. All the monthly mutual fund flow data is from the Investment Company Institute.

Our investigation here focuses on redemption rates for stock and bond funds. This choice reflects our belief that redemptions require active choices by investors whereas a significant portion of the new flows to bond and stock funds reflect allocation choices that are less responsive to current market conditions. We calculate the redemption rate as the aggregate stock (bond) fund redemptions for a given month normalized by the total assets of stock (bond) funds for that month.

We concentrate on the ratio of the redemption rate for stock funds to the redemption rate for bond funds. We find this ratio averages .814 during regime-zero and 1.063 during regime-one. Using a bootstrap, this difference is statistically significant at better than the $1 \%$ level. Changes in both stock and bond redemption rates contribute to this difference. The stock redemption rate increases from 1.4\% (regime-zero) to $1.6 \%$ (regime-one) and the bond redemption rate decreases from $1.8 \%$ (regime-zero) to $1.5 \%$ (regime-one). Bootstrap computations indicate these changes are statistically significant at better than the $1 \%$ level.

Following earlier work in the aggregate mutual fund flow literature (Warther (1995) and Edelen and Warner (2001)), we also repeat this analysis controlling for a number of potential determinants of relative

redemption dynamics. Specifically, we regress the relative redemption rate (stocks divided by bonds) on lagged values of the relative redemption rate series, relative cumulative returns over the previous six months and the six months before that, and a sequence of monthly dummy variables to capture strong seasonal variation in the relative redemption rates. We also add a dummy variable for regime-one. The coefficient on this dummy variable is positive, meaning stock (bond) fund redemptions are relatively larger (lower) in regime-one than in regime-zero, and the estimate (.058) is significant at the $1 \%$ level (t-statistic $=2.86)$. The $\mathrm{R}^{2}$ for the regression is $74 \%$. 


\section{References}

Ang, A., and G. Bekaert. "Regime Switches in Interest Rates." Journal of Business and Economic Statistics, 20 (2002a), 163-182.

Ang, A., and G. Bekaert. "Short Rate Nonlinearities and Regime Switches." Journal Of Economic Dynamics And Control, 26 (2002b), 1243-1274.

Ang, A., and G. Bekaert. "How Do Regimes Affect Asset Allocation?" Working Paper, Columbia University (2002c).

Bakshi, G., and N. Kapadia. "Delta-hedged Gains and the Negative Market Volatility Risk Premium." The Review of Financial Studies, 16 (2003), 527-566.

Barsky, R. "Why Don't the Prices of Stocks and Bonds Move Together?" American Economic Review, 79 (1989), 1132-1145.

Bekaert, G., and S. Grenadier. "Stock and Bond Pricing in an Affine Economy." Working Paper, Columbia University (2001).

Blair, B., S. Poon, and S. Taylor. "Forecasting S \& P 100 Volatility: The Incremental Information Content of Implied Volatilities and High-frequency Index Returns." Journal of Econometrics, 105 (2001), 5-26.

Bollerslev, T., and J. Wooldridge. "Quasi-maximum Likelihood Estimation and Inference in Dynamic Models with Time-varying Covariances." Econometric Reviews, 11 (1992), 143-172.

Boudoukh, J., M. Richardson, T. Smith, and R. Whitelaw. "Regime Shifts and Bond Returns." Working Paper, New York University (1999).

Campbell, J., and J. Ammer. "What Moves the Stock and Bond Markets? A Variance Decomposition for Long-term Asset Returns." The Journal of Finance, 48 (1993), 3-37.

Campbell, J., S. Grossman, and J. Wang. "Trading Volume and Serial Correlation in Stock Returns." The Quarterly Journal of Economics, 108 (1993), 905-939.

Campbell, J., M. Lettau, B. Malkiel, and Y. Xu. "Have Individual Stocks Become More Volatile? An Empirical Exploration of Idiosyncratic Risk." The Journal of Finance, 56 (2001), 1-43.

Chen, J., H. Hong, and J. Stein. "Forecasting Crashes: Trading Volume, Past Returns and Conditional Skewness in Stock Prices." Journal of Financial Economics, 61 (2001), 345-381.

Chordia, T., A. Sarkar, and A. Subrahmanyam. "Common Determinants of Bond and Stock Market Liquidity: The Impact of Financial Crises, Monetary Policy, and Mutual Fund Flows." Working Paper, Emory University, the Federal Reserve Bank of New York, and UCLA (2001).

Christensen, B., and N. Prabhala. "The Relation between Implied and Realized Volatility." Journal of Financial Economics, 50 (1998), 125-150.

Connolly, R., and C. Stivers. "Momentum and Reversals in Equity-index Returns during Periods of Abnormal Turnover and Return Dispersion." The Journal of Finance, (forthcoming 2003).

Coval, J., and T. Shumway. "Expected Option Returns." The Journal of Finance, 56 (2001), 983-1009.

David, A., and P. Veronesi. "Inflation and Earnings Uncertainty and the Volatility of Asset Prices: An Empirical Investigation." Working Paper, University of Chicago (2001). 
David, A., and P. Veronesi. "Option Prices with Uncertain Fundamentals: Theory and Evidence on the Dynamics of Implied Volatilities." Working Paper, University of Chicago (2002).

Diebold, F., J. Lee, and G. Weinbach. "Regime Shifting with Time-varying Transitions Probabilities." in C. Hargreaves, (ed.) Time Series Analysis and Cointegration, Oxford University Press (1994).

Edelen, R. and J. Warner. "Aggregate Price Effects of Institutional Trading: A Study of Mutual Fund Flow and Market Returns." Journal of Financial Economics, 59 (2001), 195-220.

Engel, C., and J. Hamilton. "Long Swings in the Dollar: Are They in the Data and Do Markets Know It?" Journal of Financial Economics, 25 (1990), 23-49.

Fama, E., and K. French. "Business Conditions and Expected Returns on Stocks and Bonds." Journal of Financial Economics, 25 (1989), 23-49.

Fleming, J. "The Quality of Market Volatility Forecasts Implied by S\&P 100 Index Options." Journal of Empirical Finance, 5 (1998), 317-345.

Fleming, J., C. Kirby, and B. Ostdiek. "Information and Volatility Linkages in the Stock, Bond, and Money Markets." Journal of Financial Economics, 49 (1998), 111-137.

Fleming, J., C. Kirby, and B. Ostdiek. "The Economic Value of Volatility Timing." The Journal of Finance, 56 (2001), 329-352.

Fleming, J., C. Kirby, and B. Ostdiek. "The Economic Value of Volatility Timing Using "Realized" Volatility." Journal of Financial Economics, 67 (2003), 473-509.

Fleming, J., B. Ostdiek, and R. Whaley. "Predicting Stock Market Volatility: A New Measure." The Journal of Futures Markets, 15 (1995), 265-302.

Fleming, M. "The Round-the-Clock Market for U.S. Treasury Securities." Economic Policy Review, Federal Reserve Bank of New York, 3 (1997), 9-32.

Forbes, K., and R. Rigobon. "No Contagion, Only Interdependence: Measuring Stock Market Co-movements." The Journal of Finance, 57 (2002), 2223-2261.

Gray, S. "Modeling the Conditional Distribution of Interest Rates as a Regime-switching Process." Journal of Financial Economics, 42 (1996), 27-62.

Gulko, L. "Decoupling." Journal of Portfolio Management, 28 (2002), 59-66.

Hamilton, J. Time-series Analysis. Princeton University Press, Princeton, New Jersey (1994).

Harris, M. and A. Raviv. "Differences of Opinion Make a Horse Race." The Review of Financial Studies, 6 (1993), 473-506.

Hartmann, P., S. Straetmans, and C. Devries. "Asset Market Linkages in Crisis Periods." Working Paper No. 71, European Central Bank (2001).

Harvey, C., and R. Huang. "The Impact of the Federal Reserve Bank's Open Market Operations." Journal of Financial Markets, 6 (2002), 223-257.

Heaton, J., and D. Lucas. "Evaluating the Effects of Incomplete Markets on Risk Sharing and Asset Pricing." Journal of Political Economy, 104 (1996), 443-487.

Keim, D., and R. Stambaugh. "Predicting Returns in Bond and Stock Markets." Journal of Financial Economics, 17 (1986), 357-390. 
Kim, C., and C. Nelson. State-space Models with Regime Switching. Cambridge: MIT Press (1999).

King, M., and S. Wadhwani. "Transmission of Volatility between Stock Markets." The Review of Financial Studies, 3 (1990), 5-33.

Kodres, L., and M. Pritsker. "A Rational Expectations Model of Financial Contagion." The Journal of Finance, 57 (2002), 769-799.

Lee, S., and K. Kim. "Does the October 1987 Crash Strengthen the Co-movements among National Stock Markets?" Review of Financial Economics, 3 (1993), 89-102.

Li, L. "Correlation of Stock and Bond Returns." Working Paper, Yale University (2002).

Lo, A. and J. Wang. "Trading Volume: Definitions, Data Analysis, and Implications of Portfolio Theory." The Review of Financial Studies, 13 (2000), 257-300.

Mamaysky, H. "Market Prices of Risk and Return Predictability in a Joint Stock-Bond Pricing Model." Working Paper, Yale School of Management (2002).

Merton, R. "An Intertemporal Capital Asset Pricing Model." Econometrica, 41 (1973), 867-887.

Newey, W., and K. West. "A Simple Positive Semi-definite, Heteroskedasticity and Autocorrelation Consistent Covariance Matrix." Econometrica, 55 (1987), 703-708.

Schwert, G. W. "Why Does Stock Market Volatility Change over Time?" The Journal of Finance, 44 (1989), 1115-1153.

Scruggs, J., and P. Glabadanidis. "Risk Premia and the Dynamic Covariance between Stock and Bond Returns." Journal of Financial and Quantitative Analysis, (forthcoming 2001).

Shalen, C. "Volume, Volatility, and the Dispersion of Beliefs." The Review of Financial Studies, 6 (1993), 405-434.

Shiller, R., and A. Beltratti. "Stock Prices and Bond Yields: Can their Comovements Be Explained in Terms of Present Value Models?" Journal of Monetary Economics, 6 (1992), 405-434.

Urich, T., and P. Wachtel. "Financial Market Responses to Monetary Policy Changes in the 1990's." Contemporary Economic Policy, 19 (2001), 254-267.

Veronesi, P. "Stock Market Overreaction to Bad News in Good Times: A Rational Expectations Equilibrium Model." The Review of Financial Studies, 12 (1999), 975-1007.

Veronesi, P. "Belief-dependent Utilities, Aversion to State-uncertainty and Asset Prices." Working Paper, University of Chicago (2001).

Wang, J. "A Model of Competitive Stock Trading Volume." Journal of Political Economy, 102 (1994), 127-168.

Warther, V. "Aggregate Mutual Fund Flows and Security Returns." Journal of Financial Economics, 39 (1995), 209-235.

Whitelaw, R. "Stock Market Risk and Returns: An Equilibrium Approach." The Review of Financial Studies, 13 (2000), 521-547. 
TABLE 1

\section{Descriptive Statistics}

This table reports the descriptive statistics for the data used in this article. S, B10, and B30 refer to the stock, 10-year Treasury bond, and 30-year Treasury bond return series, respectively. The returns are in daily percentage units. VIX is the Chicago Board Option Exchange's Volatility Index in annualized, percentage, standard deviation units. TVR is the average turnover of the firms that comprise our large-firm NYSE/AMEX portfolio, in daily percentage units. Std. Dev. denotes standard deviation and $\rho_{i}$ refers to the $i$ th autocorrelation. Panel A reports the sample moments of the data from 1986 to 2000. Panel B reports the sample moments of the data from 1988 to 2000. Panel C reports the correlation matrix. The correlation coefficients for the 1986-2000 sample period are shown in brackets and on the upper triangle. The correlation coefficients for the 1988-2000 sample period are on the lower triangle.

\begin{tabular}{lccccc}
\hline \multicolumn{5}{c}{ Panel A: Sample Moments, 1986-2000 } \\
\hline Mean & S & B10 & B30 & VIX & TVR \\
Median & 0.058 & 0.028 & 0.034 & 20.51 & 0.331 \\
Maximum & 0.090 & 0.021 & 0.021 & 19.38 & 0.311 \\
Minimum & 8.669 & 4.822 & 7.540 & 150.19 & 1.398 \\
Std. Dev. & -17.17 & -2.73 & -3.80 & 9.04 & 0.071 \\
Skewness & 0.97 & 0.446 & 0.677 & 7.83 & 0.114 \\
Excess Kurtosis & -1.86 & 0.12 & 0.25 & 4.40 & 1.60 \\
$\rho_{1}$ & 0.079 & 0.072 & 0.040 & 0.942 & 0.797 \\
$\rho_{2}$ & -0.041 & 0.009 & 0.023 & 0.892 & 0.734 \\
$\rho_{3}$ & -0.042 & -0.019 & -0.011 & 0.875 & 0.712 \\
$\rho_{10}$ & -0.017 & 0.032 & 0.038 & 0.720 & 0.687 \\
\hline
\end{tabular}


TABLE 1

(continued)

Panel B: Sample Moments, 1988-2000

\begin{tabular}{lccccc}
\hline & $\mathrm{S}$ & $\mathrm{B} 10$ & $\mathrm{~B} 30$ & $\mathrm{VIX}$ & TVR \\
Mean & 0.061 & 0.028 & 0.035 & 19.84 & 0.329 \\
Median & 0.084 & 0.021 & 0.021 & 18.69 & 0.305 \\
Maximum & 4.828 & 1.926 & 3.082 & 49.36 & 1.393 \\
Minimum & -6.592 & -2.732 & -3.805 & 9.04 & 0.071 \\
Std. Dev. & 0.892 & 0.414 & 0.633 & 6.29 & 0.329 \\
Skewness & -0.461 & -0.220 & -0.132 & 0.88 & 1.52 \\
Kurtosis & 5.828 & 2.38 & 1.79 & 0.987 & 4.48 \\
$\rho_{1}$ & 0.060 & 0.075 & 0.032 & 0.975 & 0.816 \\
$\rho_{2}$ & -0.022 & -0.005 & 0.014 & 0.956 & 0.762 \\
$\rho_{3}$ & -0.037 & -0.044 & -0.028 & 0.942 & 0.744 \\
$\rho_{10}$ & 0.001 & 0.034 & 0.040 & 0.884 & 0.735 \\
\hline
\end{tabular}

Panel C: Correlation Matrix

\begin{tabular}{lccccc}
\hline & $\mathrm{S}$ & B10 & B30 & VIX & TVR \\
\hline $\mathrm{S}$ & 1.000 & {$[0.223]$} & {$[0.250]$} & {$[-0.186]$} & {$[-0.019]$} \\
B10 & 0.218 & 1.000 & {$[0.938]$} & {$[0.045]$} & {$[0.054]$} \\
B30 & 0.250 & 0.936 & 1.000 & {$[0.039]$} & {$[0.046]$} \\
VIX & -0.133 & -0.025 & -0.030 & 1.000 & {$[0.432]$} \\
TVR & 0.015 & 0.034 & 0.025 & 0.467 & 1.000 \\
\hline
\end{tabular}


TABLE 2

\section{VIX Level and the Subsequent 22-Trading-Day Stock-Bond Return Correlation}

This table reports on the relation between the VIX level and the subsequent 22-trading-day correlation between stock and bond returns. For this table, the VIX criterion refers to the VIX level in period $t-1$. The subsequent 22 -trading-day correlation refers to the correlation between stock and bond returns over days $t$ through $t+21$, following the respective VIX $_{t-1}$. In this table, the correlations are calculated assuming that the expected daily returns for both stocks and bonds are zero, rather than the respective sample means for each 22-trading-day period. VIX is in annualized standard deviation units. The overall sample spans from 1986 through 2000.

Summary statistics of 22-trading-day stock-bond return correlations

\begin{tabular}{|c|c|c|c|c|c|c|}
\hline VIX Criterion & Observ. & Proportion of & Average & Median & $25^{\text {th }}$ Pctl & $75^{\text {th }}$ Pctl \\
\hline & & Correlations $<0$ & Corr. & Corr. & Corr. & Corr. \\
\hline All & $\mathrm{n}=3733$ & $15.62 \%$ & 0.340 & 0.420 & 0.160 & 0.599 \\
\hline VIX > $>40 \%$ & $\mathrm{n}=65$ & $53.85 \%$ & 0.062 & -0.051 & -0.191 & 0.376 \\
\hline VIX > $>35 \%$ & $\mathrm{n}=123$ & $48.78 \%$ & 0.084 & 0.043 & -0.194 & 0.375 \\
\hline VIX > $>30 \%$ & $\mathrm{n}=249$ & $46.59 \%$ & 0.079 & 0.050 & -0.231 & 0.422 \\
\hline VIX $>25 \%$ & $\mathrm{n}=713$ & $36.47 \%$ & 0.177 & 0.236 & -0.181 & 0.556 \\
\hline VIX $<20 \%$ & $n=2008$ & $6.08 \%$ & 0.415 & 0.454 & 0.269 & 0.616 \\
\hline
\end{tabular}


TABLE 3

\section{Lagged VIX and the Relation between Daily Bond and Stock Returns}

This table reports results from estimating the following regression:

$$
B_{t}=a_{0}+\left(a_{1}+a_{2} \ln \left(V I X_{t-1}\right)+a_{3} C V_{t-1}\right) S_{t}+\nu_{t}
$$

where $B_{t}$ and $S_{t}$ are the daily 10-year T-bond and stock returns, respectively; $\ln \left(V I X_{t-1}\right)$ is the natural $\log$ of the VIX in period $t-1 ; \nu_{t}$ is the residual, $C V_{t-1}$ is the additional conditioning variable noted in Panels $\mathrm{C}$ and $\mathrm{D}$, and the $a_{i}$ 's are estimated coefficients. The overall sample period is 1986 to 2000. The regression is estimated by OLS and T-statistics are in parentheses, calculated with autocorrelation and heteroskedastic consistent standard errors per the Newey and West (1987) method with five lags.

Panel A: Restrict $a_{2} \& a_{3}=0$

\begin{tabular}{lcccc}
\hline & $1 / 86-12 / 00$ & $1 / 88-12 / 00$ & $1 / 86-6 / 93$ & $7 / 93-12 / 00$ \\
\hline$a_{0}$ & 0.022 & 0.022 & 0.027 & 0.017 \\
& $(2.77)$ & $(2.95)$ & $(2.22)$ & $(1.67)$ \\
$a_{1}$ & 0.102 & 0.101 & 0.142 & 0.063 \\
& $(5.04)$ & $(6.02)$ & $(3.42)$ & $(3.18)$ \\
& & & & \\
$R^{2 \%}$ & 4.96 & 4.75 & 8.91 & 2.06 \\
\hline
\end{tabular}

Panel B: Restrict $a_{3}=0$

\begin{tabular}{lcccc}
\hline & $1 / 86-12 / 00$ & $1 / 88-12 / 00$ & $1 / 86-6 / 93$ & $7 / 93-12 / 00$ \\
\hline$a_{0}$ & 0.018 & 0.019 & 0.024 & 0.011 \\
& $(2.38)$ & $(2.59)$ & $(2.04)$ & $(1.13)$ \\
$a_{1}$ & 0.792 & 1.231 & 0.625 & 1.722 \\
& $(4.99)$ & $(9.40)$ & $(6.21)$ & $(10.94)$ \\
$a_{2}$ & -0.208 & -0.355 & -0.142 & -0.513 \\
& $(-4.33)$ & $(-8.68)$ & $(-5.24)$ & $(-10.48)$ \\
$R^{2 \%}$ & & & & \\
& 9.32 & 10.64 & 11.75 & 14.91 \\
$a_{1}+a_{2} \ln (V I X)$ & & & & 0.178 \\
$($ at the median VIX) & 0.174 & 0.192 & 0.206 & \\
$a_{1}+a_{2} \ln (V I X)$ & & & & -0.041 \\
$($ at VIX's 95 th percentile) & 0.073 & 0.012 & 0.129 & \\
$a_{1}+a_{2} \ln (V I X)$ & 0.278 & 0.360 & 0.257 & 0.480 \\
$($ at VIX's 5th percentile) & & & & \\
\hline
\end{tabular}


TABLE 3

(continued)

Panel C: $C V_{t-1}=$ Lagged 22-day stock-bond return correlation

\begin{tabular}{lcccc}
\hline & $1 / 86-12 / 00$ & $1 / 88-12 / 00$ & $1 / 86-6 / 93$ & $7 / 93-12 / 00$ \\
\hline$a_{0}$ & 0.019 & 0.018 & 0.024 & 0.011 \\
& $(2.37)$ & $(2.54)$ & $(2.07)$ & $(1.17)$ \\
$a_{1}$ & 0.504 & 0.606 & 0.570 & 1.063 \\
& $(4.84)$ & $(4.59)$ & $(4.41)$ & $(5.47)$ \\
$a_{2}$ & -0.136 & -0.173 & -0.132 & -0.311 \\
& $(-4.35)$ & $(-4.18)$ & $(-4.00)$ & $(-5.07)$ \\
$a_{3}$ & 0.241 & 0.260 & 0.054 & 0.211 \\
& $(5.03)$ & $(9.16)$ & $(0.51)$ & $(4.72)$ \\
& & & & \\
$R^{2}(\%)$ & 13.06 & 14.39 & 11.83 & 16.93 \\
\hline
\end{tabular}

Panel D: $C V_{t-1}=$ Asian-Russian Crisis Dummy ${ }^{1}$

\begin{tabular}{cccc}
\hline & $1 / 86-12 / 00$ & $1 / 86-12 / 00$ & $1 / 86-12 / 00$ \\
& Asian \& Russian crisis & Asian only & Russian only \\
\hline$a_{0}$ & 0.018 & 0.018 & 0.018 \\
& $(2.33)$ & $(2.35)$ & $(2.35)$ \\
$a_{1}$ & 0.747 & 0.793 & 0.748 \\
& $(6.37)$ & $(5.24)$ & $(5.92)$ \\
$a_{2}$ & -0.188 & -0.207 & -0.190 \\
& $(-5.39)$ & $(-4.51)$ & $(-5.03)$ \\
$a_{3}$ & -0.196 & -0.184 & -0.186 \\
& $(-6.63)$ & $(-5.04)$ & $(-5.10)$ \\
& & & \\
$R^{2}(\%)$ & 11.16 & 9.83 & 10.54 \\
\hline
\end{tabular}

1. For the 'Asian crisis only' model, $C V_{t-1}=1$ over the October 1 to December 31, 1997 period, and zero otherwise. For the 'Russian crisis only' model, $C V_{t-1}=1$ over the July 6 to December 31, 1998 period, and zero otherwise. For the Asian \& Russian crisis, $C V_{t-1}=1$ over both crisis periods. 
TABLE 4

\section{Daily VIX Changes and the Stock-Bond Return Relation}

This table reports on the association between daily VIX changes and the stock-bond return relation. The VIX-change criteria below refers to the percentile range for the daily change in VIX, from the most negative changes ( 0 to $5^{\text {th }}$ percentile) to the most positive (95 to $100^{\text {th }}$ percentile). In the table, $\mu$ refers to the mean, $\sigma$ refers to the standard deviation, and $\rho$ refers to the correlation for the stock and bond return observations in each respective VIX-change sub-sample. The correlations in this table are calculated assuming that the daily expected returns for both the stock and bonds are zero, rather than the sub-sample mean. $B 10$ and $S$ refer to the ten-year bond return and stock-market return, respectively. The rows below that are denoted with an * exclude the stock market crash of October 19, 1987 from the sub-sample. The sample period is 1986 through 2000.

Summary statistics for the stock and bond returns, sorted by the daily VIX change

\begin{tabular}{|c|c|c|c|c|c|c|}
\hline VIX-Change Criteria & Observ. & $\mu_{B 10}$ & $\sigma_{B 10}$ & $\mu_{S}$ & $\sigma_{S}$ & $\rho_{B 10, S}$ \\
\hline All & $\mathrm{n}=3754$ & 0.028 & 0.446 & 0.059 & 0.969 & 0.223 \\
\hline 0 to $5^{\text {th }}$ pctl & $\mathrm{n}=188$ & 0.120 & 0.591 & 1.481 & 1.188 & 0.206 \\
\hline 0 to $25^{\text {th }}$ petl & $\mathrm{n}=936$ & 0.114 & 0.457 & 0.724 & 0.871 & 0.287 \\
\hline $25^{\text {th }}$ to $50^{t h}$ pctl & $\mathrm{n}=937$ & 0.063 & 0.382 & 0.212 & 0.508 & 0.361 \\
\hline $50^{t h}$ to $75^{t h}$ pctl & $\mathrm{n}=936$ & 0.013 & 0.421 & 0.002 & 0.573 & 0.352 \\
\hline $75^{\text {th }}$ to $100^{t h}$ petl & $\mathrm{n}=936$ & -0.078 & 0.493 & -0.703 & 1.166 & 0.112 \\
\hline$* 75^{t h}$ to $100^{t h}$ pctl & $\mathrm{n}=935$ & -0.079 & 0.493 & -0.685 & 1.035 & 0.138 \\
\hline $95^{t h}$ to $100^{t h}$ pctl & $\mathrm{n}=188$ & -0.044 & 0.658 & -1.891 & 1.737 & -0.055 \\
\hline${ }^{*} 95^{t h}$ to $100^{t h}$ pctl & $\mathrm{n}=187$ & -0.047 & 0.659 & -1.810 & 1.330 & -0.030 \\
\hline
\end{tabular}


TABLE 5

\section{Stock Turnover and the Subsequent 22-trading-day Stock-Bond Return Correlation}

This table reports on the relation between stock turnover and the subsequent 22-trading-day correlation between stock and bond returns. For this table, the DTVR criterion refers to the percentile range of our detrended turnover measure. $D T V R_{t-1}=\left[\frac{1}{5}\left(\sum_{i=1}^{5} \ln \left(T V R_{t-i}\right)\right]-\left[\frac{1}{245}\left(\sum_{i=6}^{250} \ln \left(T V R_{t-i}\right)\right]\right.\right.$ where $\mathrm{TVR}_{t}$ is the average turnover of the firms that comprise our U.S. large-firm portfolio in day $t$. The subsequent 22trading-day correlation refers to the correlation between stock and bond returns over periods $t$ through $t+21$, following the respective $\mathrm{DTVR}_{t-1}$. In this table, the correlations are calculated assuming that the expected daily returns for both stocks and bonds are zero, rather than the respective sample means for each 22-trading-day period. The overall sample spans from 1986 through 2000.

Summary statistics of 22-trading-day stock-bond return correlations

\begin{tabular}{|c|c|c|c|c|c|c|}
\hline DTVR Criterion & Observ. & $\begin{array}{c}\text { Proportion of } \\
\text { Correlations }<0\end{array}$ & $\begin{array}{c}\text { Average } \\
\text { Corr. }\end{array}$ & $\begin{array}{l}\text { Median } \\
\text { Corr. }\end{array}$ & $\begin{array}{c}25^{t h} \text { Pctl } \\
\text { Corr. }\end{array}$ & $\begin{array}{c}75^{t h} \text { Pctl } \\
\text { Corr. }\end{array}$ \\
\hline All & $\mathrm{n}=3734$ & $15.61 \%$ & 0.341 & 0.420 & 0.160 & 0.599 \\
\hline $95^{t h}$ to $100^{t h}$ pctl & $\mathrm{n}=187$ & $42.78 \%$ & 0.074 & 0.054 & -0.185 & 0.324 \\
\hline $90^{t h}$ to $100^{t h}$ petl & $\mathrm{n}=374$ & $34.22 \%$ & 0.170 & 0.184 & -0.121 & 0.471 \\
\hline $75^{t h}$ to $100^{t h}$ pctl & $\mathrm{n}=933$ & $21.22 \%$ & 0.304 & 0.374 & 0.071 & 0.578 \\
\hline $0^{t h}$ to $25^{t h}$ pctl & $\mathrm{n}=933$ & $11.68 \%$ & 0.374 & 0.452 & 0.230 & 0.617 \\
\hline
\end{tabular}


TABLE 6

\section{Stock Turnover and the Relation between Daily Bond and Stock Returns}

This table reports results from estimating the following regression:

$$
B_{t}=a_{0}+\left(a_{1}+a_{2} D T V R_{t-1}+a_{3} C V_{t-1}\right) S_{t}+\nu_{t}
$$

where $B_{t}$ and $S_{t}$ are the daily 10-year T-bond and stock returns, respectively; $D T V R_{t-1}$ is our lagged detrended stock turnover, as defined in Table $5 ; \nu_{t}$ is the residual, $C V_{t-1}$ is the additional conditioning variable noted in Panels $\mathrm{C}$ and $\mathrm{D}$, and the $a_{i}$ 's are estimated coefficients. The overall sample period is 1986 to 2000. The regression is estimated by OLS and T-statistics are in parentheses, calculated with autocorrelation and heteroskedastic consistent standard errors per the Newey and West (1987) method with five lags.

Panel A: Restrict $a_{2} \& a_{3}=0$

\begin{tabular}{lcccc}
\hline & $1 / 86-12 / 00$ & $1 / 88-12 / 00$ & $1 / 86-6 / 93$ & $7 / 93-12 / 00$ \\
\hline$a_{0}$ & 0.022 & 0.022 & 0.027 & 0.017 \\
& $(2.77)$ & $(2.95)$ & $(2.22)$ & $(1.67)$ \\
$a_{1}$ & 0.102 & 0.101 & 0.142 & 0.063 \\
& $(5.04)$ & $(6.02)$ & $(3.42)$ & $(3.18)$ \\
& & & & \\
$R^{2 \%}$ & 4.96 & 4.75 & 8.91 & 2.06 \\
\hline
\end{tabular}

Panel B: Restrict $a_{3}=0$

\begin{tabular}{lcccc}
\hline & $1 / 86-12 / 00$ & $1 / 88-12 / 00$ & $1 / 86-6 / 93$ & $7 / 93-12 / 00$ \\
\hline$a_{0}$ & 0.021 & 0.022 & 0.024 & 0.018 \\
& $(2.71)$ & $(2.98)$ & $(2.09)$ & $(1.76)$ \\
$a_{1}$ & 0.137 & 0.124 & 0.174 & 0.101 \\
& $(8.75)$ & $(8.05)$ & $(6.66)$ & $(4.60)$ \\
$a_{2}$ & -0.334 & -0.348 & -0.322 & -0.345 \\
& $(-6.81)$ & $(-4.38)$ & $(-5.05)$ & $(-3.22)$ \\
$R^{2 \%}$ & & & & 3.47 \\
$a_{1}+a_{2} D T V R$ & 7.47 & 6.50 & 12.13 & 0.080 \\
$($ at the median DTVR) & & & & 0.180 \\
$a_{1}+a_{2} D T V R$ & 0.128 & 0.115 & & 0.007 \\
(at DTVR's 95th percentile) & & & 0.095 & \\
$a_{1}+a_{2} D T V R$ & 0.051 & 0.034 & & 0.168 \\
$($ at DTVR's 5th percentile) & & & & \\
\hline
\end{tabular}


TABLE 6

(continued)

Panel C: $C V_{t-1}=$ Lagged 22-day stock-bond return correlation

\begin{tabular}{lcccc}
\hline & $1 / 86-12 / 00$ & $1 / 88-12 / 00$ & $1 / 86-6 / 93$ & $7 / 93-12 / 00$ \\
\hline$a_{0}$ & 0.020 & 0.019 & 0.024 & 0.013 \\
& $(5.43)$ & $(4.41)$ & $(2.11)$ & $(1.38)$ \\
$a_{1}$ & 0.071 & 0.061 & 0.138 & 0.056 \\
& $(5.43)$ & $(4.71)$ & $(4.20)$ & $(3.27)$ \\
$a_{2}$ & -0.216 & -0.091 & -0.298 & -0.037 \\
& $(-3.49)$ & $(-1.33)$ & $(-3.98)$ & $(-0.41)$ \\
$a_{3}$ & 0.268 & 0.319 & 0.090 & 0.367 \\
& $(4.98)$ & $(11.19)$ & $(0.84)$ & $(10.20)$ \\
& & & & \\
$R^{2}(\%)$ & 12.42 & 13.50 & 12.36 & 14.56 \\
\hline
\end{tabular}

Panel D: $C V_{t-1}=$ Asian-Russian Crisis Dummy ${ }^{1}$

\begin{tabular}{cccc}
\hline & $1 / 86-12 / 00$ & $1 / 86-12 / 00$ & $1 / 86-12 / 00$ \\
& Asian \& Russian crisis & Asian only & Russian only \\
\hline$a_{0}$ & 0.020 & 0.020 & 0.020 \\
& $(2.59)$ & $(2.67)$ & $(2.64)$ \\
$a_{1}$ & 0.164 & 0.146 & 0.154 \\
& $(9.64)$ & $(9.17)$ & $(9.20)$ \\
$a_{2}$ & -0.330 & -0.345 & -0.319 \\
& $(-6.39)$ & $(-7.01)$ & $(-6.26)$ \\
$a_{3}$ & -0.234 & -0.222 & -0.224 \\
& $(-7.97)$ & $(-7.14)$ & $(-6.31)$ \\
& & & \\
$R^{2}(\%)$ & 10.14 & 8.21 & 9.27 \\
\hline
\end{tabular}

1. For the 'Asian crisis only' model, $C V_{t-1}=1$ over the October 1 to December 31, 1997 period, and zero otherwise. For the 'Russian crisis only' model, $C V_{t-1}=1$ over the July 6 to December 31, 1998 period, and zero otherwise. For the Asian \& Russian crisis, $C V_{t-1}=1$ over both crisis periods. 
TABLE 7

\section{Stock Turnover Shocks and the Stock-Bond Return Relation}

This table reports on the association between stock turnover shocks and the stock-bond return relation. The relative turnover (RTO) criteria below refers to the percentile range of our stock turnover shock, as detailed in Section IV.B. In the table, $\mu$ refers to the mean, $\sigma$ refers to the standard deviation, and $\rho$ refers to the correlation for the stock and bond return observations in each respective RTO sub-sample. $B 10$ and $S$ refer to the ten-year bond return and stock-market return, respectively. The rows below that are denoted with an ${ }^{*}$ exclude the stock market crash of October 19, 1987 from the sub-sample. The overall sample spans from 1986 through 2000.

Summary statistics for the stock and bond returns, sorted by $\mathrm{RTO}_{t}$

\begin{tabular}{lcccccc}
\hline RTO Criteria & Observ. & $\mu_{B 10}$ & $\sigma_{B 10}$ & $\mu_{S}$ & $\sigma_{S}$ & $\rho_{B 10, S}$ \\
\hline All & $\mathrm{n}=3755$ & 0.028 & 0.446 & 0.058 & 0.968 & 0.223 \\
0 to $5^{\text {th }}$ pctl & $\mathrm{n}=188$ & -0.026 & 0.384 & 0.046 & 0.582 & 0.275 \\
& & & & & & \\
0 to $25^{\text {th }}$ pctl & $\mathrm{n}=939$ & -0.009 & 0.378 & 0.023 & 0.604 & 0.209 \\
& & & & & & \\
$25^{\text {th }}$ to $50^{\text {th }}$ pctl & $\mathrm{n}=939$ & -0.013 & 0.423 & 0.050 & 0.714 & 0.292 \\
& & & & & & \\
$50^{\text {th }}$ to $75^{\text {th }}$ pctl & $\mathrm{n}=939$ & 0.034 & 0.439 & 0.048 & 0.967 & 0.216 \\
& & & & & & \\
$75^{\text {th }}$ to $100^{\text {th }}$ pctl & $\mathrm{n}=938$ & 0.099 & 0.522 & 0.113 & 1.393 & 0.209 \\
$* 75^{\text {th }}$ to $100^{\text {th }}$ pctl & $\mathrm{n}=937$ & 0.099 & 0.522 & 0.131 & 1.274 & 0.240 \\
N $^{\text {th }}$ to $105^{\text {th }}$ to $100^{\text {th }}$ pctl & $\mathrm{n}=188$ & 0.115 & 0.677 & -0.048 & 2.061 & 0.157 \\
\hline
\end{tabular}


TABLE 8

The Relation between Daily Bond and Stock Returns in a Regime-Shifting Model

This table reports on the following regime-shifting model:

$$
B_{t}=a_{0}^{s}+a_{1} B_{t-1}+a_{2}^{s} S_{t}+\epsilon_{t}
$$

where $B_{t}$ and $S_{t}$ are the daily 10-year T-bond and stock returns, respectively; $\epsilon_{t}$ is the residual; and the $a$ 's are estimated coefficients. The superscript $s$ indicates regime 0 or regime $1 . p$ and $q$ are transition probabilities where $p=\operatorname{Pr}\left(s_{t}=0 \mid s_{t-1}=0\right)$, and $q=\operatorname{Pr}\left(s_{t}=1 \mid s_{t-1}=1\right)$. The sample period is 1986 to 2000. T-statistics are in parentheses for the estimated coefficients and standard errors are in brackets for the estimated probabilities. Panel A reports the coefficient estimates and Panel B reports the sample moments for each regime, where an observation is classified as belonging to a particular regime if the probability is greater than $80 \%$.

Panel A: Coefficient estimates

\begin{tabular}{lcccc}
\hline & \multicolumn{2}{c}{$1 / 86-12 / 00$} & \multicolumn{2}{c}{$1 / 88-12 / 00$} \\
\hline$a_{0}^{0}$ & -0.0088 & $(-1.07)$ & -0.0060 & $(-0.70)$ \\
$a_{0}^{1}$ & 0.0544 & $(4.07)$ & 0.0523 & $(3.97)$ \\
$a_{1}$ & 0.0575 & $(3.88)$ & 0.0621 & $(3.90)$ \\
$a_{2}^{0}$ & 0.3044 & $(22.7)$ & 0.3035 & $(19.7)$ \\
$a_{2}^{1}$ & -0.050 & $(-5.17)$ & -0.062 & $(-5.40)$ \\
$p$ & 0.9941 & {$[0.0026]$} & 0.9931 & {$[0.0034]$} \\
$q$ & 0.9860 & {$[0.0059]$} & 0.9847 & {$[0.0074]$} \\
\hline
\end{tabular}

Panel B: Sample moments for each regime

\begin{tabular}{lccccccc}
\hline & & \multicolumn{2}{c}{ Stock Returns } & & T-Bond Returns & \\
Regime & Observ. & Mean & St.Dev. & Mean & St. Dev. & Correlation $\left(B_{t}, S_{t}\right)$ \\
\hline 1986-2000 & & & & & & \\
All observations & $\mathrm{n}=3754$ & 0.0589 & 0.969 & 0.0281 & 0.446 & 0.222 \\
Regime-zero & $\mathrm{n}=2527$ & 0.0799 & 0.741 & 0.0175 & 0.459 & 0.520 \\
Regime-one & $\mathrm{n}=828$ & 0.0128 & 1.521 & 0.0602 & 0.432 & -0.203 \\
& & & & & & \\
1988-2000 & & & & & & 0.218 \\
All observations & $\mathrm{n}=3254$ & 0.0613 & 0.892 & 0.0282 & 0.414 & 0.517 \\
Regime-zero & $\mathrm{n}=2143$ & 0.0709 & 0.710 & 0.0166 & 0.429 & -0.250 \\
Regime-one & $\mathrm{n}=771$ & 0.0347 & 1.301 & 0.0548 & 0.385 & \\
\hline
\end{tabular}


TABLE 9

\section{The Extended Regime-Shifting Model for Stock and Bond Returns with Lagged VIX}

This table reports the results for the following regime-switching model.

$$
B_{t}=a_{0}^{s}+a_{1} B_{t-1}+a_{2}^{s} S_{t}+\epsilon_{t}
$$

where the regime variable $s_{t}$ has time-varying transition probabilities:

$$
p\left(s_{t}=j \mid s_{t-1}=j ; I_{t-1}\right)=\frac{e^{c_{j}+d_{j} \ln \left(V I X_{t-1}\right)}}{1+e^{c_{j}+d_{j} \ln \left(V I X_{t-1}\right)}}, j=0,1 .
$$

where $I_{t-1}$ is the information set at $t-1$, the $c_{j}$ 's and $d_{j}$ 's are estimated coefficients, and the other terms are as defined in Table 8. The sample period is 1988 to 2000. T-statistics are in parentheses. Panel A reports the coefficient estimates and Panel B reports the sample moments for each regime, where an observation is classified as belonging to a particular regime if the probability is greater than $80 \%$.

\begin{tabular}{lcc}
\multicolumn{3}{c}{ Panel A: Coefficient estimates } \\
\hline$a_{0}^{0}$ & -0.0156 & $(-1.51)$ \\
$a_{0}^{1}$ & 0.0558 & $(4.26)$ \\
$a_{1}$ & 0.0577 & $(3.63)$ \\
$a_{2}^{0}$ & 0.3430 & $(14.7)$ \\
$a_{2}^{1}$ & -0.0609 & $(-4.99)$ \\
$c_{0}$ & 8.9163 & $(2.93)$ \\
$d_{0}$ & -1.8327 & $(-1.86)$ \\
$c_{1}$ & -1.6240 & $(-0.55)$ \\
$d_{1}$ & 1.5090 & $(1.59)$ \\
\hline
\end{tabular}

Panel B: Sample moments for each regime

\begin{tabular}{lcccccc}
\hline & & \multicolumn{3}{c}{ Stock Returns } & & \multicolumn{2}{c}{ T-Bond Returns } & \\
Regime & Observ. & Mean & St.Dev. & Mean & St. Dev. & Correlation $\left(B_{t}, S_{t}\right)$ \\
\hline Regime-zero & $\mathrm{n}=1741$ & 0.0607 & 0.695 & -0.0142 & 0.447 & 0.617 \\
Regime-one & $\mathrm{n}=671$ & 0.0015 & 1.39 & 0.0407 & 0.393 & -0.333 \\
\hline
\end{tabular}


FIGURE 1

Stock-Bond Return Correlations, Volatility Index, and Turnover
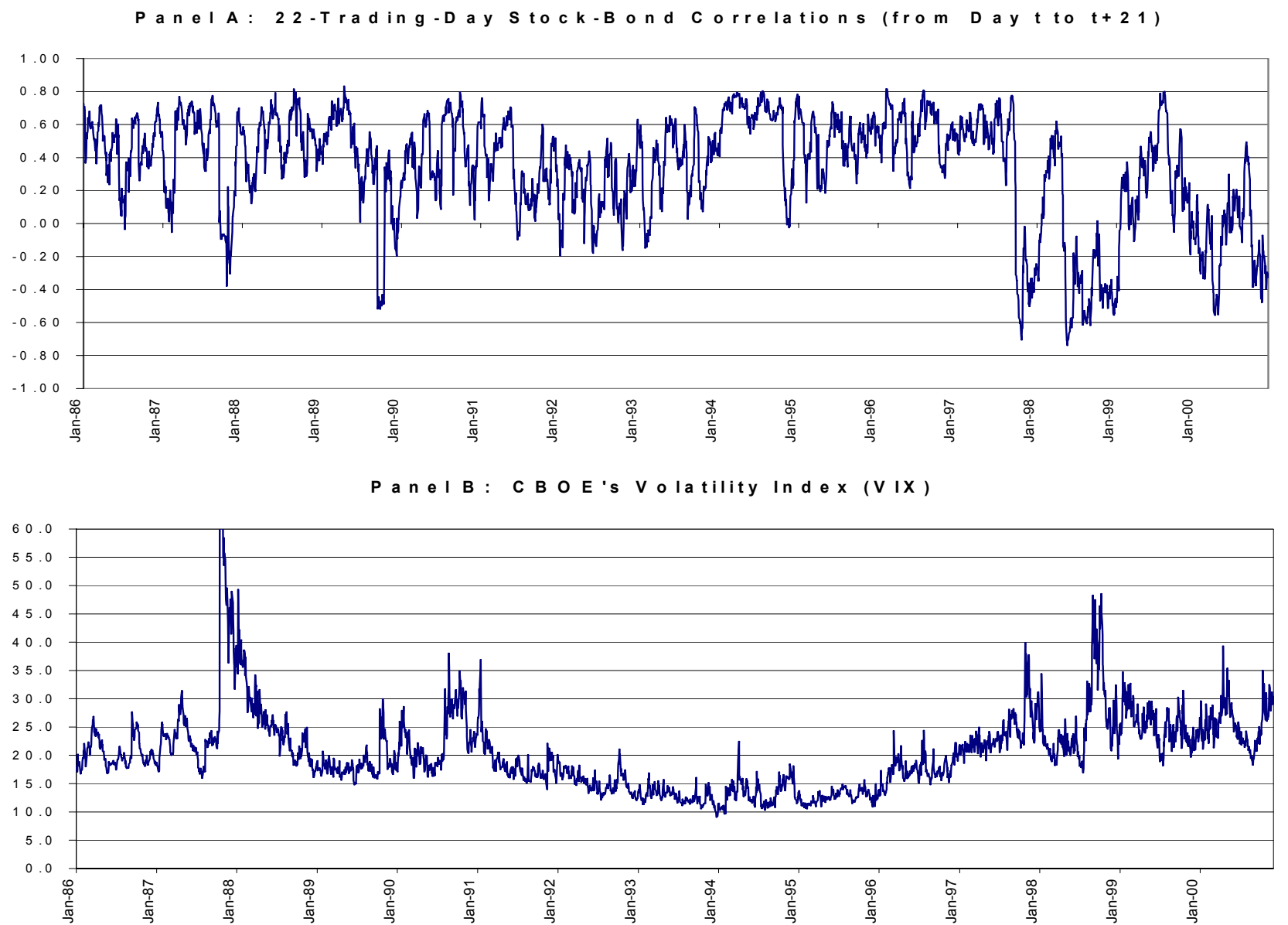

Pane I C: Lagged Large-firm Turnover (average of days t-1 to t-5)

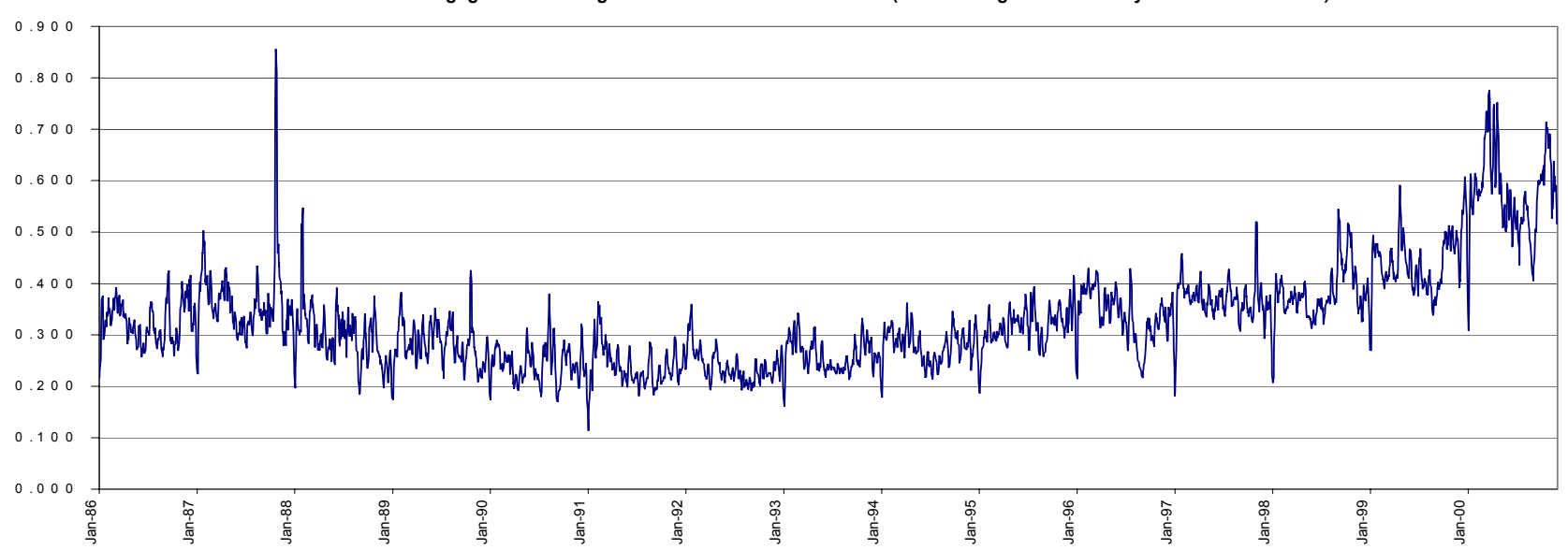

This figure displays the time-series of 22-trading-day correlations between stock and 10-year Treasury bond returns over days $t$ to $t+21$ (Panel A), the CBOE's Volatility Index (VIX) at day $t$ (Panel B), and the average turnover of the firms in our large-firm portfolio over days $t-1$ through $t-5$ (Panel C). The sample spans 1986 to 2000. 
FIGURE 2

\section{Detrended Turnover (DTVR) and Relative Turnover (RTO)}

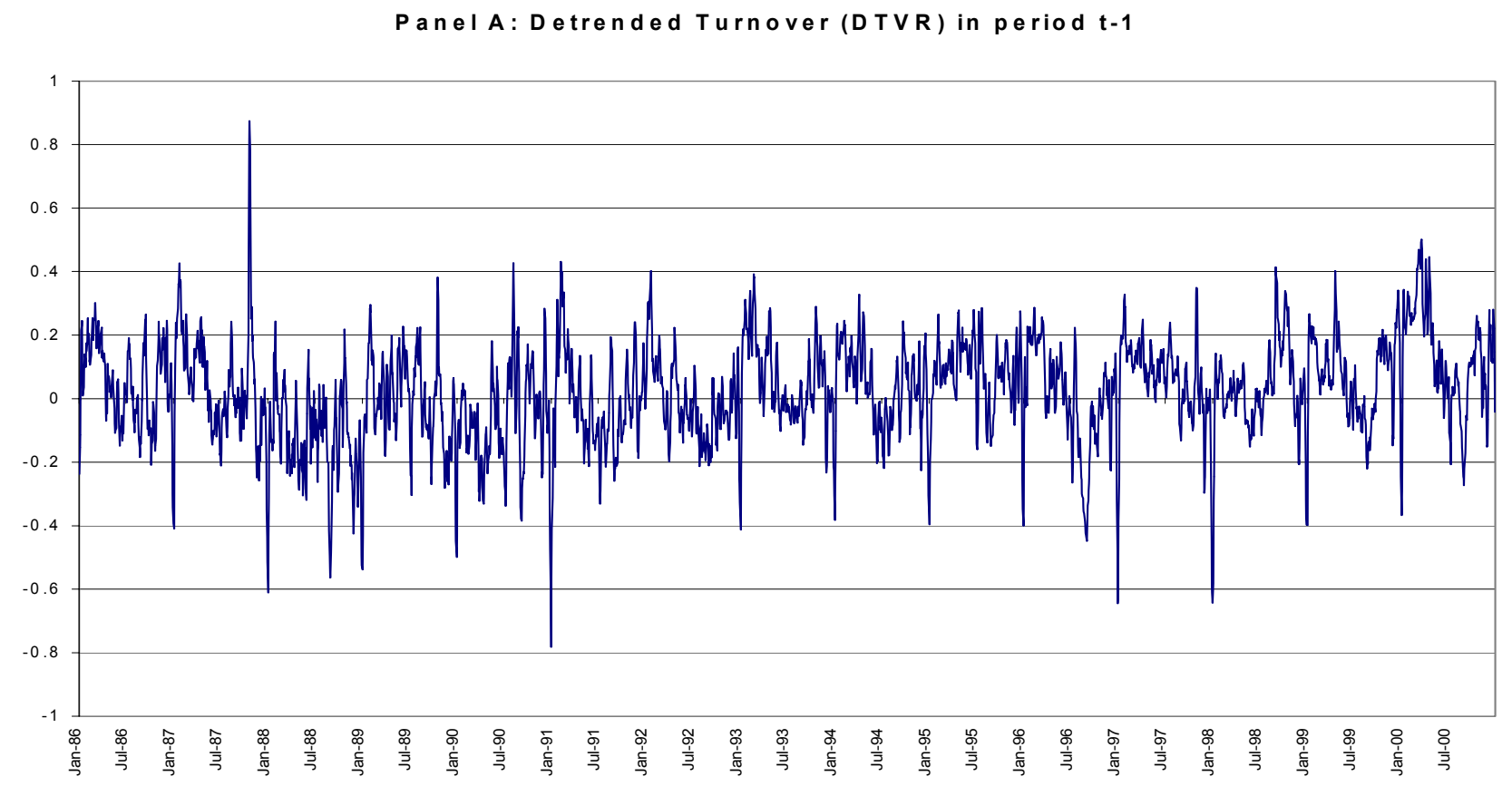

Panel B: RTO in period $t$

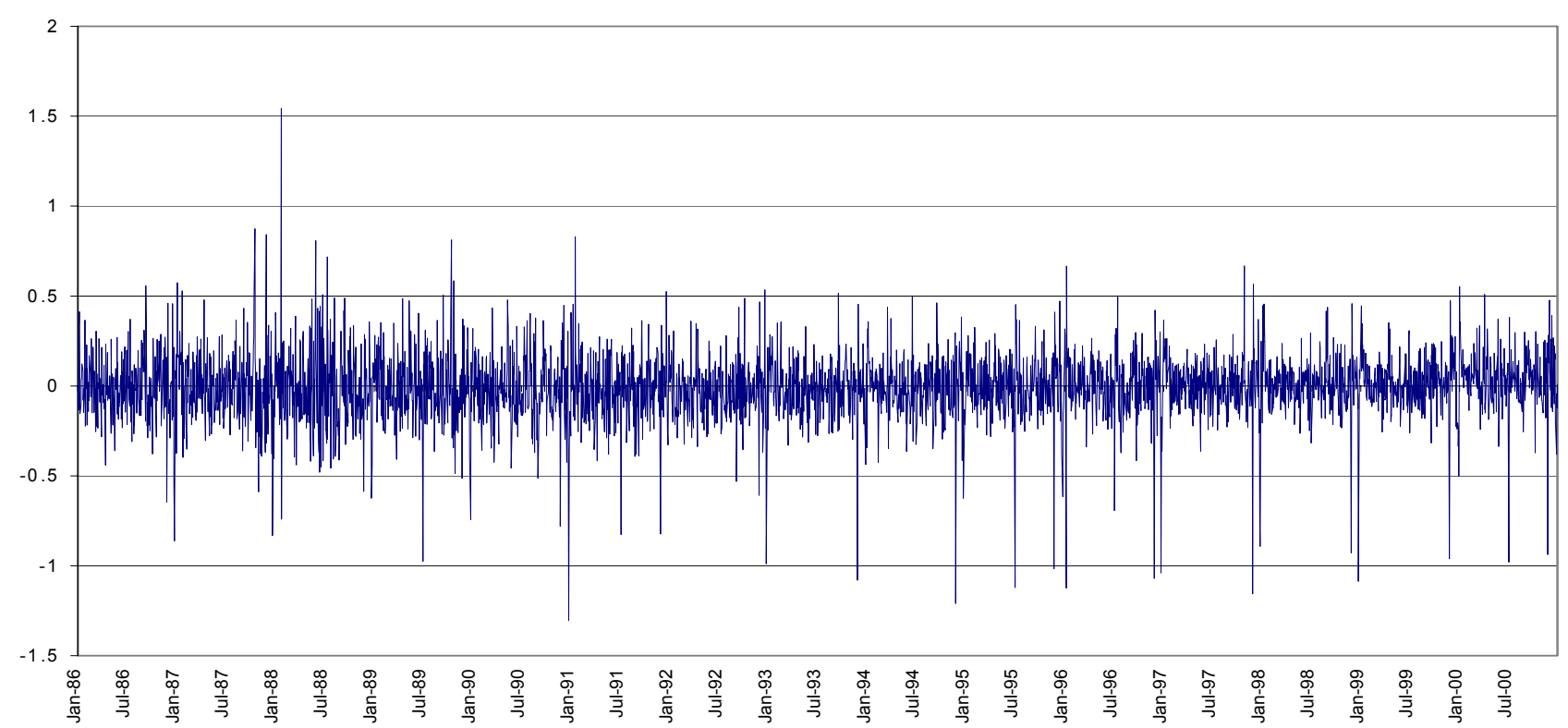

This figure display our lagged, detrended turnover $\left(\mathrm{DTVR}_{\mathrm{t}-1}\right)$ in Panel A and our relative turnover $\left(\mathrm{RTO}_{\mathrm{t}}\right)$ in Panel B. Both measures are formed from the daily turnover of firms in the largest sizebased, decile-portfolio of NYSE/AMEX stocks. See Section IV.B for details. The sample period is 1986 to 2000. 
FIGURE 3

\section{Regime Probabilities for Constant Transition Probability Model}

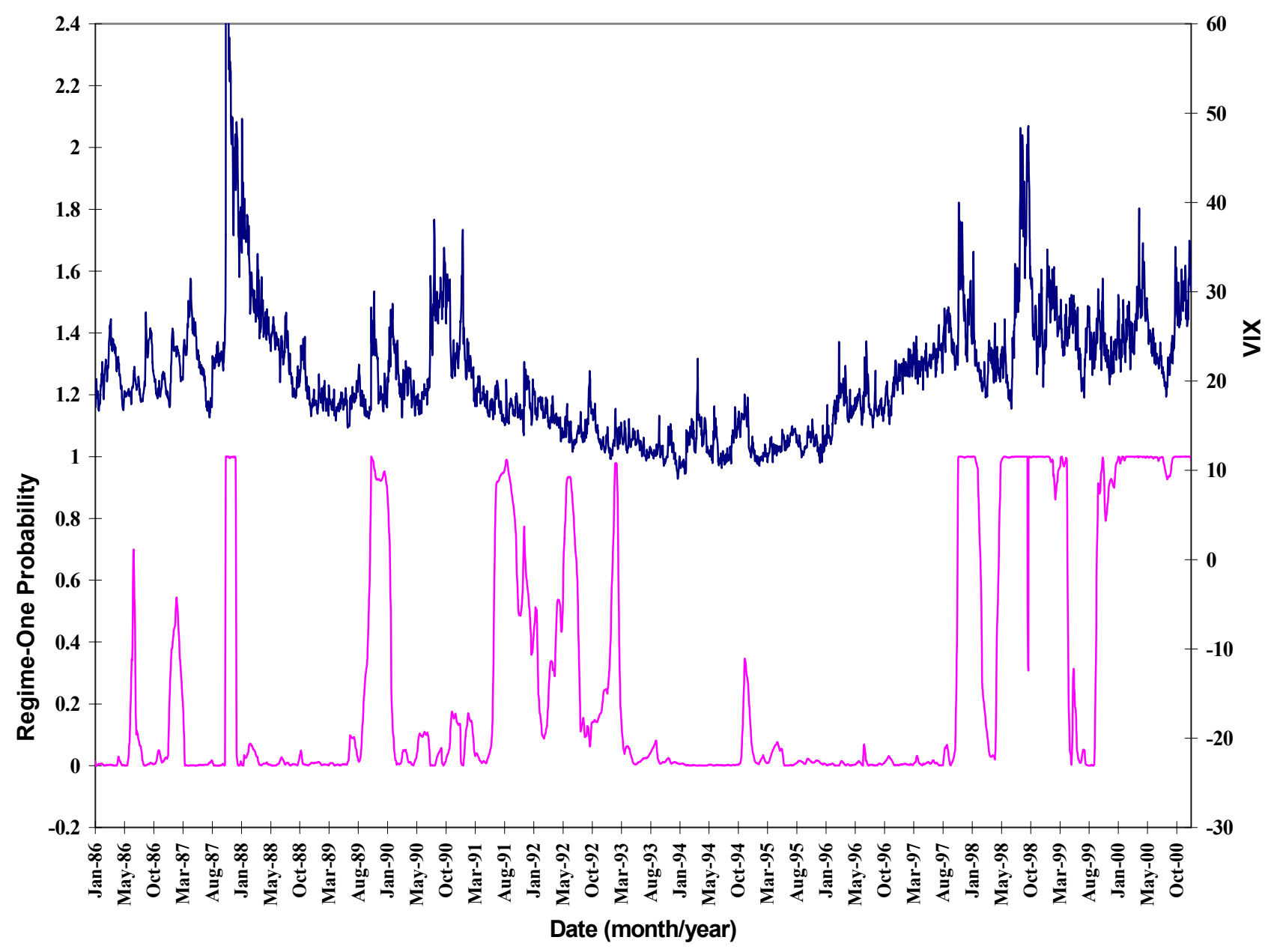

This figure displays the CBOE's Volatility Index (upper series) and the smooth probability of being in regime-one (lower series) from the basic regime-shifting model in Table 8 for the 10 -year Treasury bond returns. The sample period is 1986 to 2000 . 
FIGURE 4

\section{Regime Probabilities for Time-varying Transition Probability Model}

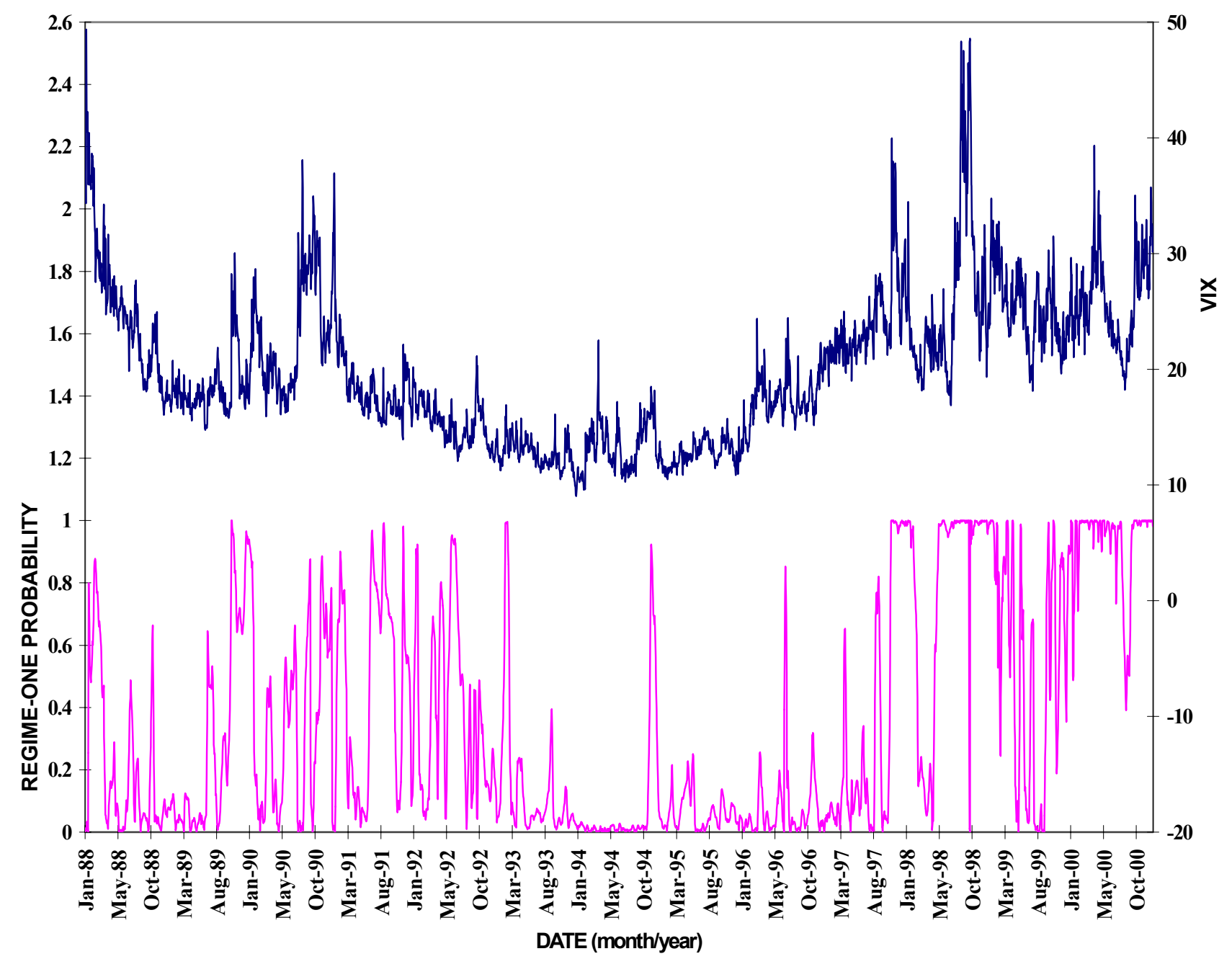

This figure displays the CBOE's Volatility Index (upper series) and the smooth probability of being in regime-one (lower series) from the extended regime-shifting model in Table 9 for the 10year Treasury bond returns. The sample period is 1988 to 2000 . 